Article

\title{
Investigation of the Physical Processes Involved in GNSS Amplitude Scintillations at High Latitude: A Case Study
}

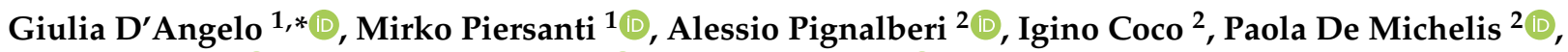

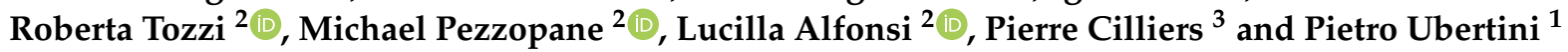 \\ 1 INAF-Istituto di Astrofisica e Planetologia Spaziali, Via del Fosso del Cavaliere 100, 00133 Roma, Italy; \\ mirko.piersanti@inaf.it (M.P.); pietro.ubertini@inaf.it (P.U.) \\ 2 Istituto Nazionale di Geofisica e Vulcanologia, Via di Vigna Murata 605, 00143 Roma, Italy; \\ alessio.pignalberi@ingv.it (A.P.); igino.coco@ingv.it (I.C.); paola.demichelis@ingv.it (P.D.M.); \\ roberta.tozzi@ingv.it (R.T.); michael.pezzopane@ingv.it (M.P.); lucilla.alfonsi@ingv.it (L.A.) \\ 3 South African National Space Agency (SANSA), Space Science Directorate, Hermanus 7200, South Africa; \\ pjcilliers@sansa.org.za \\ * Correspondence: giulia.dangelo@inaf.it
}

Citation: D'Angelo, G.; Piersanti, M.; Pignalberi, A.; Coco, I.; De Michelis, P.; Tozzi, R.; Pezzopane, M.; Alfonsi,

L.; Cilliers, P.; Ubertini, P.

Investigation of the Physical

Processes Involved in GNSS

Amplitude Scintillations at High Latitude: A Case Study. Remote Sens. 2021, 13, 2493. https://doi.org/ $10.3390 /$ rs13132493

Academic Editors: Luca Spogli and P.T. Jayachandran

Received: 19 May 2021

Accepted: 19 June 2021

Published: 25 June 2021

Publisher's Note: MDPI stays neutral with regard to jurisdictional claims in published maps and institutional affiliations.

Copyright: (c) 2021 by the authors. Licensee MDPI, Basel, Switzerland. This article is an open access article distributed under the terms and conditions of the Creative Commons Attribution (CC BY) license (https:// creativecommons.org/licenses/by/ $4.0 /)$

\begin{abstract}
The storm onset on 7 September 2017, triggered several variations in the ionospheric electron density, causing severe phase fluctuations at polar latitudes in both hemispheres. In addition, although quite rare at high latitudes, clear amplitude scintillations were recorded by two Global Navigation Satellite System receivers during the main phase of the storm. This work attempted to investigate the physical mechanisms triggering the observed amplitude scintillations, with the aim of identifying the conditions favoring such events. We investigated the ionospheric background and other conditions that prevailed when the irregularities formed and moved, following a multiobservations approach. Specifically, we combined information from scintillation parameters and recorded by multi-constellation (GPS, GLONASS and Galileo) receivers located at Concordia station $\left(75.10^{\circ} \mathrm{S}, 123.35^{\circ} \mathrm{E}\right)$ and SANAE IV base $\left(71.67^{\circ} \mathrm{S}, 2.84^{\circ} \mathrm{W}\right)$, with measurements acquired by the Special Sensor Ultraviolet Spectrographic Imager on board the Defense Meteorological Satellite Program satellites, the Super Dual Auroral Radar Network, the Swarm constellation and groundbased magnetometers. Besides confirming the high degree of complexity of the ionospheric dynamics, our multi-instrument observation identified the physical conditions that likely favor the occurrence of amplitude scintillations at high latitudes. Results suggest that the necessary conditions for the observation of this type of scintillation in high-latitude regions are high levels of ionization and a strong variability of plasma dynamics. Both of these conditions are typically featured during high solar activity.
\end{abstract}

Keywords: GNSS amplitude scintillations; multi-constellation receivers; high-latitude ionosphere; geomagnetic storm; space weather

\section{Introduction}

Ionospheric scintillation is the most intriguing and challenging effect observed on L-band signals (100 MHz-4 GHz), such as those used by the Global Navigation Satellite System (GNSS). Scintillations are rapid and random fluctuations of the trans-ionospheric signals received by ground-based and space-borne instruments. They are induced by ionospheric irregularities, which are defined as regions of enhanced or depleted plasma density relative to background encountered by the electromagnetic wave in its travel through the ionosphere (e.g., References [1,2]). Electron density gradients result in refractive index variations, which give rise to refraction and diffraction processes distorting the original wave front of the received signals. Refraction induces mainly phase fluctuations. The received phase changes because the electromagnetic wave enters a medium of either increased or decreased phase velocity. Diffraction implies that the impinging electromagnetic 
wave enters the ionosphere with a spatially uniform phase and exits the ionosphere with a spatially irregular phase. These irregular phases may combine either constructively or destructively, giving rise to amplitude and phase scintillations (e.g., References [2-4]). This diffraction pattern is produced by ionospheric irregularities near the first Fresnel scale, which, in the case of GNSS signal transmitted at L1 $=1575.42 \mathrm{MHz}$ frequency, is in the range $300-400 \mathrm{~m}$ for irregularity residing in the F-region ionosphere [3].

The regions mostly affected by scintillation phenomena are the equatorial and the auroral/polar latitudes [5-7]; however, the physical mechanisms involved in the formation of the irregularities are significantly different in the two regions. At high latitudes, the main phenomena triggering GNSS signal degradation are as follows: (i) large-scale electron density gradients (auroral blobs, polar cap patches, etc.); (ii) precipitating energetic particles within the auroral oval and cusp; and (iii) variation of the plasma velocity [7-14]. Geomagnetic forcing and solar activity control such events. Indeed, under high geomagnetic activity, the solar wind-magnetosphere-ionosphere coupling leads to an increased formation of ionospheric irregularities that, consequently, can result in an increased probability of GNSS signal disruptions [15-23].

To quantify the scintillation, the $S_{4}$ and the $\sigma_{\varphi}$ indices are derived from GNSS receivers to characterize the amplitude and the phase fluctuations, respectively. $S_{4}$ represents the normalized standard deviation of the amplitude over $1 \mathrm{~min}$, while $\sigma_{\varphi}$ is the standard deviation of the detrended phase over $1 \mathrm{~min}$ [24]. Since to derive scintillation indices, it is necessary to remove a long-term trend-consisting of the Doppler shift due to satellite receiver relative motion, slowly varying background ionosphere and some hardware effects-usually a sixth-order Butterworth filter with a $0.1 \mathrm{~Hz}$ cutoff frequency is used (see References [24-26]). However, since amplitude and phase fluctuations in a received electromagnetic wave may be diffractive or refractive, the choice of this cutoff frequency is not unique and should be made carefully; otherwise, the refractive variations are also included (see, e.g., Reference [27] and references therein). This leads to case of "phase without amplitude scintillation", i.e., phase fluctuations misinterpreted as phase scintillations, because the value of the cutoff frequency does not affect the determination of the amplitude scintillation index, but it does affect the phase scintillation index very much (see References [27-29] and references therein). This is especially true at high latitude (see, e.g., References $[8,11,22,23,30,31]$ ), where a very high and variable ionospheric drift velocity ( 100 to $1500 \mathrm{~m} / \mathrm{s}$; see, e.g., Reference [32]) exists. Such velocity directly affect the cutoff frequency since it linearly depends on the relative velocity between the receiver, the ionosphere and the GPS satellite (e.g., References $[27,29,33]$ ).

The choice of the best cutoff frequency is crucial for high accuracy positioning. This is because diffraction is stochastic so the degradation due to ionospheric scintillations cannot be corrected or mitigated. On the other hand, since the refraction is deterministic, phase fluctuations, which are typically produced by ionospheric irregularities at wave number much smaller than the Fresnel scale, can be corrected by using multi-frequency measurements. However, such correction is beyond the scope of this work that is focused on the scientific understanding of the scintillation events.

In this paper, we report and discuss how the peculiar conditions triggered by the 2017 September storm resulted in amplitude scintillations. Following a multi-instrumental approach that combines information derived from ground-based and space-based observations, we investigated the complex spatial-temporal context in which the selected events occurred, also identifying the physical conditions that likely favor the occurrence of amplitude scintillations at high latitudes.

The paper is structured as follows. Section 2 provides an overview of all the different types of data here considered and their preprocessing; Section 3 describes the analyzed geomagnetic storm and Section 4 the observed scintillation events. In Section 5, the large amount of information and data described in previous sections is interpreted and discussed separately for each GNSS receiver. Finally, Section 6 summarizes the results. 


\section{Data and Methods}

The present investigation is mainly based on GNSS observations, recorded by selected ground-based receivers located in Antarctica at Concordia station and SANAE IV base (Upper Atmosphere Physics and Radiopropagation Working Group, [34]). The geographic and Altitude Adjusted Corrected GeoMagnetic (AACGM, [35]) coordinates of these stations are reported in Table 1 together with their locations and owners. Each station is equipped with a Septentrio PolaRxS Ionospheric Scintillation Monitoring Receiver (ISMR), which is a multi-frequency, multi-constellation receiver dedicated to ionospheric monitoring and space weather applications [36,37]. In particular, the ISMR is able to provide access to raw phase and post-correlation In-phase (I) and Quadrature $(\mathrm{Q})$ components sampled at $50 \mathrm{~Hz}$ not only from the United States GPS system of navigation satellites, but also from the Russian GLONASS, the European Galileo, from the Chinese Beidou, the QZSS and satellites of the Satellite Based Augmentation System (SBAS) constellations.

Table 1. Locations, identifiers, geographic and Altitude Adjusted Corrected GeoMagnetic coordinates (AACGM Lat and AACGM Lon) of the ISMRs used in this study. ISMR = Ionospheric Scintillation Monitoring Receiver.

\begin{tabular}{ccllccc}
\hline Location & Station ID & Owner & Latitude & Longitude & AACGM Lat & AACGM Lon \\
\hline Concordia & DMC0 & INGV & $75.10^{\circ} \mathrm{S}$ & $123.35^{\circ} \mathrm{E}$ & $88.98^{\circ} \mathrm{S}$ & $57.64^{\circ} \mathrm{E}$ \\
SANAE & SNA0 & INGV & $71.67^{\circ} \mathrm{S}$ & $2.84^{\circ} \mathrm{W}$ & $61.83^{\circ} \mathrm{S}$ & $44.91^{\circ} \mathrm{E}$ \\
\hline
\end{tabular}

From the $50 \mathrm{~Hz}$ samples, ISMRs provide, among others, RINEX data and values of the scintillation indices at different time intervals for all visible satellites and at multiple frequencies. In this work, 1-min data of phase $\left(\sigma_{\varphi}\right)$ and amplitude $\left(S_{4}\right)$ scintillation indices [25] at L1 (GPS) and E1 (Galileo) central frequency (1575.42 MHz) are considered.

To detrend the carrier phase, used in the $\sigma_{\varphi}$ we adopted the standard scheme based on a sixth-order Butterworth filter with a $0.1 \mathrm{~Hz}$ cutoff frequency bearing in mind that $\sigma_{\varphi}$ includes phase fluctuations due to ionospheric refraction not related to scintillation and is dependent on the plasma convection velocity (see, e.g., References [27,29]). This choice, indeed, does not affect our discussions that are based on the different behavior of $S_{4}$ and $\sigma_{\varphi}$ according to the different scale sizes of the probed irregularities.

To reduce the impact on measurements of longer paths through the ionosphere, we vertically projected scintillation indices according to the method described in Spogli et al. $[7,11]$ by fixing the height of the Ionospheric Piercing Point (IPP) at $350 \mathrm{~km}$ according to D'Angelo et al. [16,17]. In addition, following D'Angelo et al. [38] we applied a mask of $30^{\circ}$ on the elevation angle of the satellites to reduce the impact of non-scintillation related tracking errors (such as multipath). According to the convergence time of the Butterworth filter, we included in the analysis only data characterized by a lock time greater than $240 \mathrm{~s}$ [39].

To investigate the ionospheric scenario leading to the observed scintillations in terms of the occurrence of electron density irregularities, we collected and processed raw GNSS measurements provided by the permanent stations of the University NAVSTAR Consortium (UNAVCO), located in polar, auroral and subauroral regions of the Southern Hemisphere, including also measurements recorded by the DMC0 and SNA0 receivers. In particular, we processed GNSS measurements to obtain calibrated Total Electron Content (TEC) data. We performed the TEC calibration by using the technique by Ciraolo et al. [40] and Cesaroni et al. [41]. We also calculated the Rate of TEC change (ROT) that allows inferring the scale sizes of the ionospheric irregularities $[8,42,43]$ and also retrieving information on their dynamics.

Since in situ and ground-based observations can enhance the understanding of the ionospheric features associated with signal scintillations, we resorted to a wide variety of additional data sources. For instance, we analyzed and interpreted data from the Special Sensor Ultraviolet Spectrographic Imager (SSUSI) on board the Defense Meteorological 
Satellite Program (DMSP) satellites F16-F19 to investigate the link between high-latitude particle precipitation and the occurrence of irregularities. SSUSI, indeed, consists of sensors intended to provide global auroral observations at five wavelengths in the ultraviolet range (115-180 nm), with high spatial resolution (7-9 $\mathrm{km}$ at nadir) by scanning across the track of the DMSP trajectory every $15 \mathrm{~s}[44,45]$. In this study to represent the aurora we used the emission from N2 Lyman-Birge-Hopfield long filter (LBHL) band (165-180 nm), according to Jin and Oksavik [46].

In addition, we leveraged on the ionospheric electrostatic potential provided by the Super Dual Auroral Radar Network (SuperDARN, [47]) in the form of convection maps to better characterize the dynamics of high latitudes. Although such maps provide only an average picture of the high-latitude ionosphere dynamics, they can be useful to link the local and global evolution of polar cap dynamics to the conditions of the Earth's magnetosphere and the interplanetary medium (especially in those regions where the number of the observed echoes is not negligible).

Moreover, in situ measurements of plasma density collected in the topside ionosphere by Langmuir probes on board the Swarm constellation [48] were analyzed to investigate the electron density distribution during the geomagnetic storm. Specifically, we studied the occurrence of polar cap patches (PCPs) identified by using the Swarm IPDxIRP Level 2 product, which is capable of detecting the occurrence of PCPs by means of electron density measurements taken at magnetic latitudes higher than $77^{\circ}$ with a time sampling of $2 \mathrm{~Hz}$. The PCPs correspond to plasma density variations that are at least twice the background density [49]. Values of the PCP flag different from zero indicates the presence of patches along Swarm orbit. Furthermore, to correlate the electron density variability with the storm's drivers, we computed and analyzed the electron density root mean square $(\mathrm{rms})$ for each time series corresponding to a polar crossing above $\left|70^{\circ}\right|$ of magnetic latitude, for two of the three satellites of the constellation (specifically for Swarm A and Swarm B). Since during the geomagnetic storm here analyzed, Swarm A was flying at an altitude of around $445 \mathrm{~km}$ and Swarm B of around $510 \mathrm{~km}$, this data allow us to estimate the average variability of the electron density through the polar cap at different altitudes and times of the day.

Data collected by the fluxgate magnetometers co-located with the selected GNSS receivers were used to support the description of the ionospheric area entering the field of view of the receiver.

OMNI solar wind and IMF data with a 1-min resolution [50] were used to relate the interplanetary medium conditions to the ionospheric scenario where irregularities causing scintillations appear and evolve.

Finally, to investigate the high-latitude ionosphere response in terms of geomagnetic indices, we used $A E$ (Auroral Electrojet), $A U$ (Auroral Upper) and $A L$ (Auroral Lower) indices at a 1-min resolution [51].

Tables 2 and 3 summarize the measurements chosen for the investigation, specifying the sampling time, the instrument type and the location at which such measurements were acquired. Specifically, Table 2 summarizes the satellite observations, while Table 3 summarizes the ground-based ones except for the GNSS receivers, already described above and summarized in Table 1. 
Table 2. Satellite, height of flight, instrument type, measurements and sampling time of the space-based observations used in this study.

\begin{tabular}{|c|c|c|c|c|}
\hline \multicolumn{5}{|c|}{ Satellite Observations } \\
\hline Satellite & Height of Flight & Instrument Type & Measurements & Sampling Time \\
\hline $\begin{array}{l}\text { Defense Meteorological } \\
\text { Satellite Program } \\
\text { (DMSP) satellites }\end{array}$ & $\sim 830 \mathrm{~km}$ & $\begin{array}{c}\text { Special Sensor } \\
\text { Ultraviolet } \\
\text { Spectrographic Imager } \\
\text { (SSUSI) }\end{array}$ & $\begin{array}{c}\text { emission from N2 } \\
\text { LBHL band (165-180 } \\
\text { nm) }\end{array}$ & $15 \mathrm{~s}$ for each scan \\
\hline $\begin{array}{c}\text { Swarm A and B } \\
\text { satellites }\end{array}$ & $\begin{array}{c}\sim 445 \mathrm{~km} \text { and } \sim 510 \mathrm{~km} \\
\text { respectively }\end{array}$ & Langmuir probes & Electron density & $0.5 \mathrm{~s}$ \\
\hline
\end{tabular}

Table 3. Instrument type, location, station identifier, measurements and sampling time of the groundbased observations used in this study.

\begin{tabular}{|c|c|c|c|c|}
\hline \multicolumn{5}{|c|}{ Ground-based Observations } \\
\hline $\begin{array}{l}\text { Instrument } \\
\text { Type }\end{array}$ & Location & Station ID & Measurements & Sampling Time \\
\hline $\begin{array}{c}\text { Fluxgate } \\
\text { magnetometers }\end{array}$ & $\begin{array}{l}\text { Concordia } \\
\text { SANAE IV }\end{array}$ & $\begin{array}{l}\text { DMC } \\
\text { SNA }\end{array}$ & $\mathrm{H}, \mathrm{Z}$ & $\begin{array}{c}1 \mathrm{~min} \\
1 \mathrm{~s}\end{array}$ \\
\hline $\begin{array}{c}\text { Super Dual } \\
\text { Auroral Radar } \\
\text { Network } \\
\text { (SuperDARN) }\end{array}$ & $\begin{array}{l}\text { High latitudes } \\
\text { Mid latitudes } \\
\text { Polar Cap }\end{array}$ & & $\begin{array}{l}\text { Convection } \\
\text { velocity and } \\
\text { spectral width }\end{array}$ & $2 \mathrm{~min}$ \\
\hline
\end{tabular}

\section{The September 2017 Geomagnetic Storm: An Overview}

The period under investigation is featured by a geomagnetic storm, which was caused by the intense solar activity that occurred between September 4 and 10, 2017. The main source of the storm was the Active Region AR2673 (Catania sunspot group 46), which produced four X-class eruptions including the strongest of Solar Cycle 24 on September 6, 2017, with a flare intensity of X9.3.

An Interplanetary Coronal Mass Ejection (ICME) was observed to start on September 6. This triggered a class G4 storm (severe geomagnetic storm-NOAA Kp $=8, \mathrm{Ap}=106$ ) whose main phase was on September 7 and 8, 2017 [52,53]. In addition, between September 5 and 8 , increased values of the protons flux with energy $>10 \mathrm{MeV}$ were recorded, resulting in several proton events [52]. As reported in Piersanti et al. [54], the perturbed period was characterized by a first interplanetary shock followed by a magnetic cloud on September 7 and a second interplanetary shock followed by a second magnetic cloud on September 8 . Here we focus on the second shock and magnetic cloud.

Figure 1 displays the velocity and dynamic pressure of the solar wind (SW) and its Interplanetary Magnetic Field (IMF), along with the high-latitude geomagnetic response in terms of $A E, A L$ and $A U$ indices. According to the red curve in panel a, on 8 September $B_{\mathrm{Z}, \mathrm{IMF}}$ shows two periods of pronounced negative values. The first started with the minimum value recorded during the day $(-33 \mathrm{nT})$, occurred between 00:00 and 02:30 UT, which was the reminisce of the first magnetic cloud. The second started at around 11:30 UT and ended around 18:10 UT, when $B_{\mathrm{Z}, \mathrm{IMF}}$ settled near weakly negative values. During the second period of negative values, shortly before 15:00 UT, two fast fluctuations of $B_{\mathrm{Z}, \mathrm{IMF}}$ around zero occurred. At the same time, a peak (with a maximum of $\sim 10 \mathrm{nPa}$ ) in the SW dynamic pressure (red curve in panel $b$ ) was recorded. The negative excursions of the $B_{\mathrm{Z}, \mathrm{IMF}}$ component resulted in intense particle precipitation at high latitudes that produced enhancements in the substorm activity. Indeed, during southward $B_{Z, I M F}$, intense eastward and westward auroral electrojets ([55] and references therein) were recorded, as testified by the trend of the upper and lower auroral electrojet current indices, respectively ( $A U$ and $A L$ : green and red curves, respectively, in panel c). This suggests the presence of favorable 
conditions to the formation of ionospheric plasma irregularities causing scintillations on the GNSS signals [56].
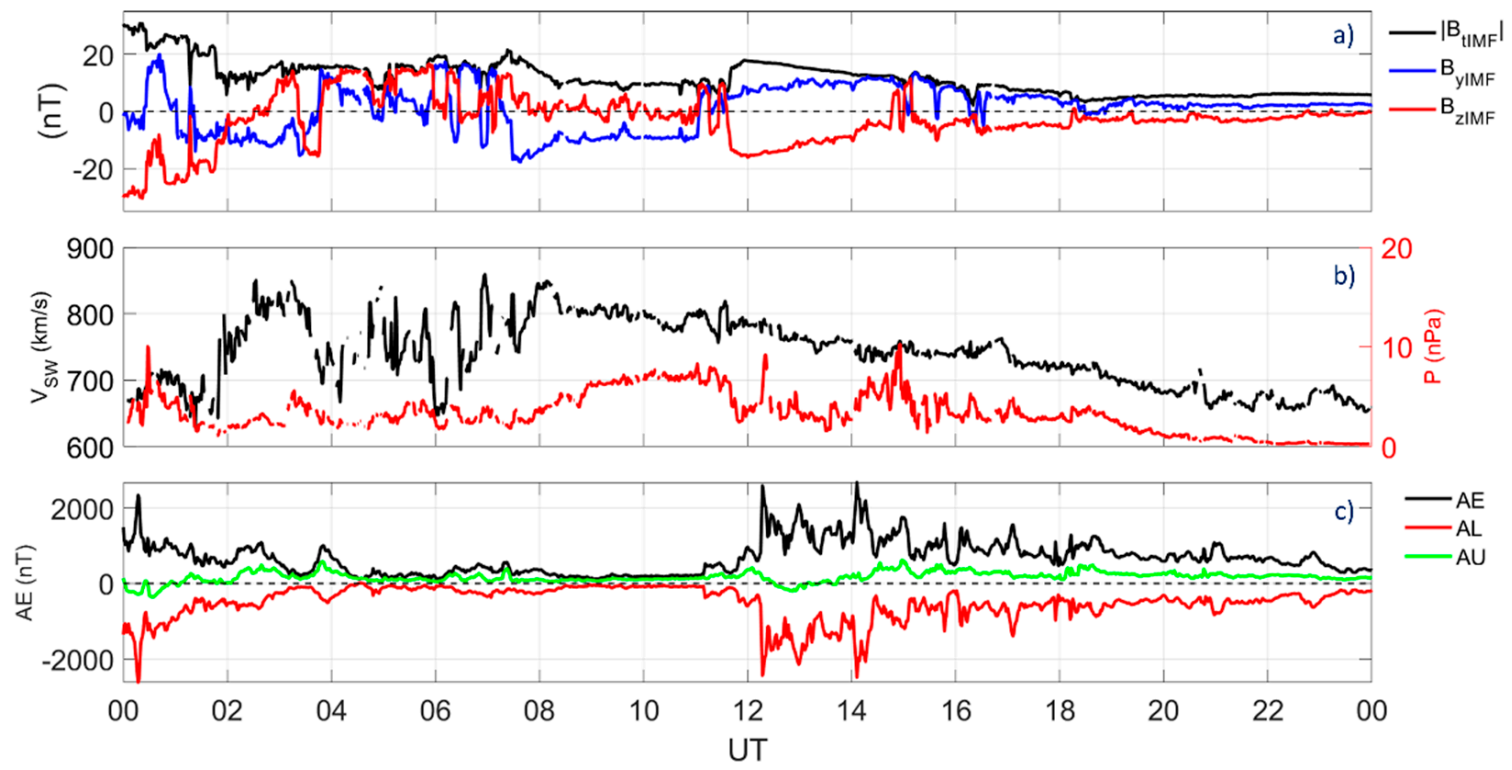

Figure 1. Interplanetary space observations and geomagnetic response at high latitudes on 8 September 2017. From top to bottom: (a) Interplanetary Magnetic Field (IMF) intensity (black), IMF $B_{\mathrm{y}, \mathrm{IMF}}$ component (blue) and IMF $B_{\mathrm{z} \text {,IMF }}$ component (red); (b) solar wind (SW) velocity $V_{\mathrm{SW}}$ (black) and SW dynamic pressure $P$ (red); and (c) $A E$ (black), $A U$ (green) and the $A L$ (red) indices. IMF and SW data are taken from the OMNI database.

\section{Scintillation Events}

Figures 2 and 3 show TEC (a), ROT (b), $\sigma_{\varphi}(\mathrm{c})$ and $S_{4}(\mathrm{~d})$ time profiles recorded on 8 September 2017, by the GNSS receivers SNA0 and DMC0 located at SANAE IV and Concordia stations, respectively. Different colors refer to different satellites entering the receivers' fields of view. For both GNSS stations, TEC data (panels a in Figures 2 and 3) show profiles that deviated from the quiet time diurnal variation, which typically maximize in the local noon/post noon sector (around 12:00 UT for the SNA0 receiver and around 08:00 UT for the DMC0 receiver). The increase of TEC was characterized by values much higher than expected for quiet times, which usually do not exceed $20 \mathrm{TECu}$ (Total Electron Content unit, $1 \mathrm{TECu}=10^{16} \mathrm{el} \mathrm{m}^{-2}$, e.g., References [46,57]).

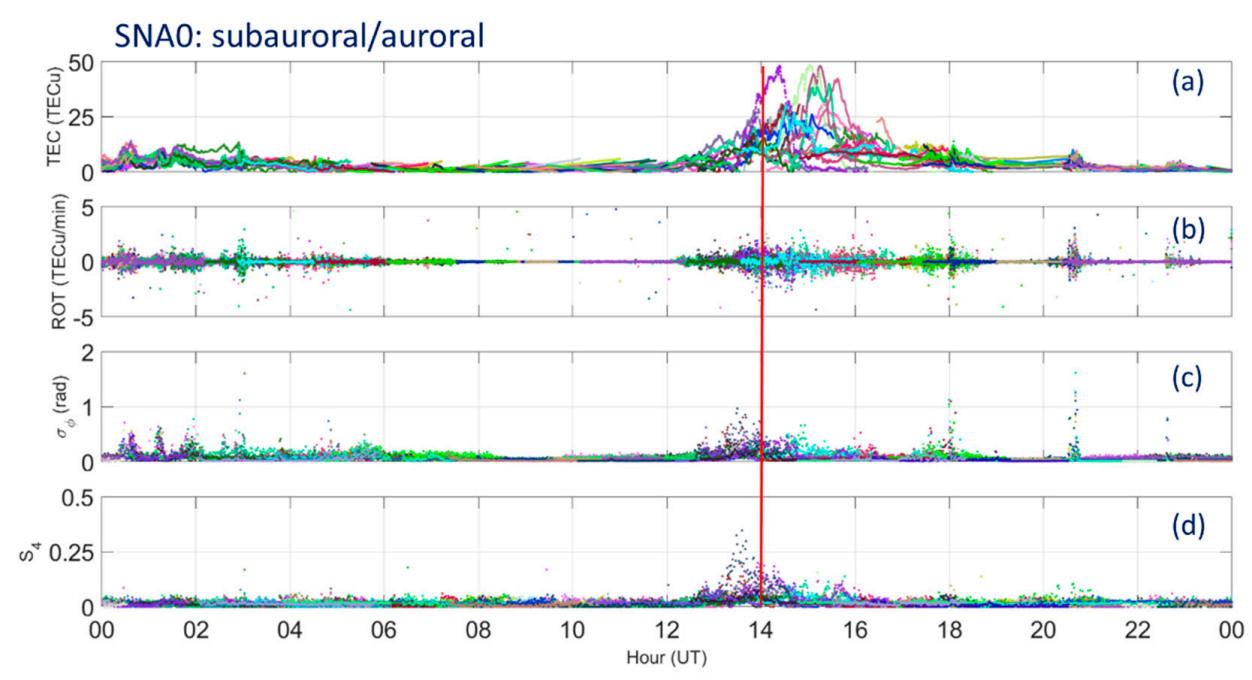

Figure 2. GNSS data from the receiver located at SANAE IV base (SNA0) on 8 September 2017. From top to bottom: Total Electron Content (TEC, a), Rate of TEC change (ROT, b), phase scintillation index $\left(\sigma_{\varphi}, \mathbf{c}\right)$ and amplitude scintillation index $\left(S_{4}\right.$, d). Different colors refers to different satellites in view of the receiver. Red vertical line highlights the local magnetic noon. 


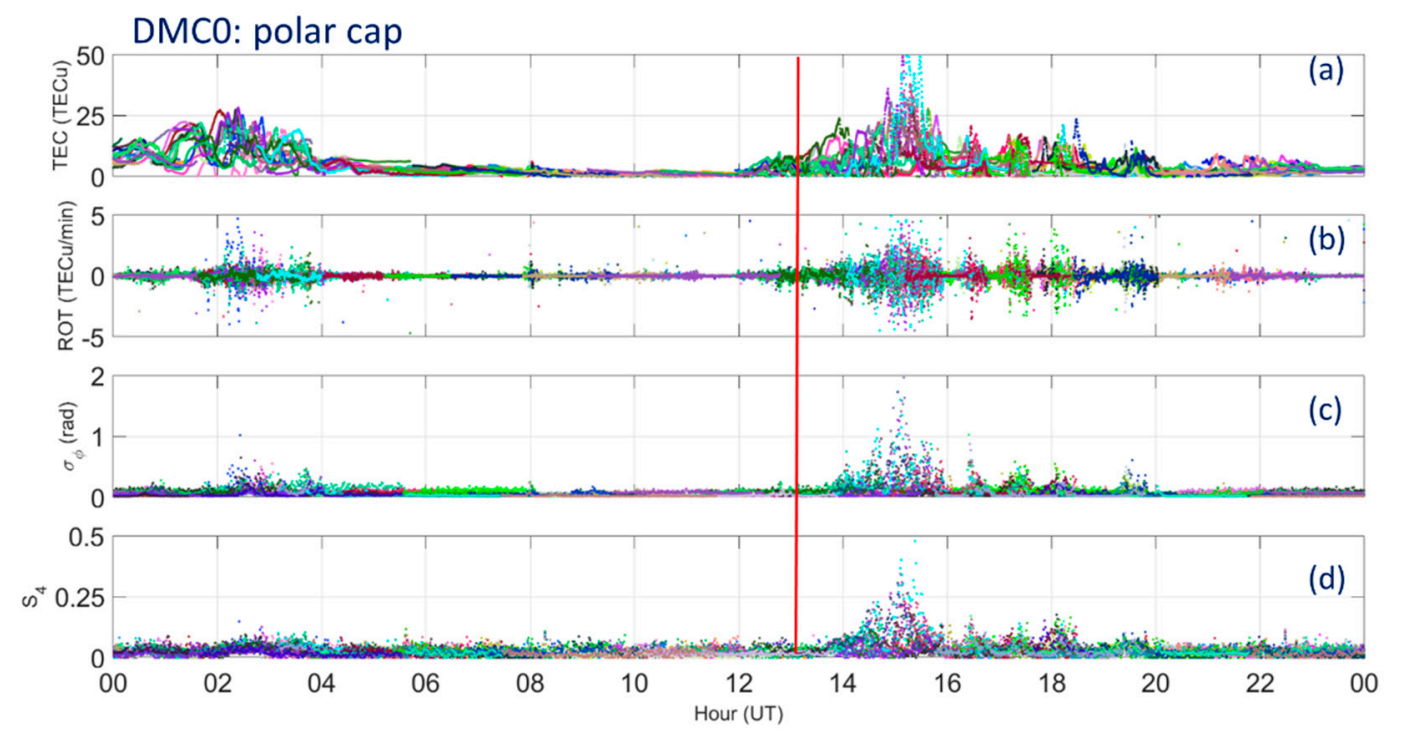

Figure 3. GNSS data from the receiver located at Concordia station (DMC0) on 8 September 2017. From top to bottom: Total Electron Content (TEC, a), Rate of TEC change (ROT, b), phase scintillation index $\left(\sigma_{\varphi}, \mathbf{c}\right)$ and amplitude scintillation index $\left(S_{4}, \mathrm{~d}\right)$. Different colors refer to different satellites in view of the receiver. Red vertical line highlights the local magnetic noon.

The SNA0 receiver recorded TEC increases (Figure 2a) during the nighttime (00:00-04:00 UT), in the early afternoon (12:00-17:00 UT), around 18:00 UT and between 20:00 and 21:00 UT. Such increases were characterized by rapid TEC fluctuations, as demonstrated by ROT data (Figure $2 b$ ), and associated with moderate/strong phase fluctuations (Figure 2c) with low or no amplitude scintillations, except between 12:00 and 16:00 UT when SNA0 recorded moderate amplitude scintillations $\left(\mathrm{S}_{4} \sim 0.4\right.$, Figure $2 \mathrm{~d}$ ) affecting several satellites in view. We recall that, according to Alfonsi et al. [8], a scintillation event is considered of moderate to intense level when $S_{4}$ and $\sigma_{\varphi}$ are both greater than 0.25 , while scintillation is considered to be weak when $S_{4}$ and $\sigma_{\varphi}$ are both between 0.1 and 0.25 . In addition, only when both $S_{4}$ and $\sigma_{\varphi}$ simultaneously exceed 0.25 the scintillation is actually occurring (see, e.g., References [27,29]).

The DMC0 receiver recorded TEC increases between 00:00 and 04:00 UT and between 12:00 and 20:00 UT (Figure 3a), which were characterized by intense ROT fluctuations (Figure 3b). Simultaneously, the receiver recorded moderate/intense phase fluctuations (Figure 3c), often associated with weak/moderate amplitude scintillations (Figure 3d). The values of $S_{4}$ index recorded by the DMC0 receiver during the day (Figure 3d) are higher than those recorded by the SNA0 receiver, even though the data treatment was the same for both stations.

\section{Discussion}

In order to understand the physical mechanisms causing the different behaviors in the scintillation profiles recorded by receivers, hereafter we split the discussion about scintillation events recorded at SANAE IV base from those recorded at Concordia station. Moreover, as the receiver located at SANAE IV base recorded phase without amplitude scintillation events, we discuss actual scintillation events separately, in which both the phase and the amplitude indices increase, from those showing only phase fluctuations.

\subsection{SANAE: Scintillation Events}

During the second period of pronounced negative $B_{Z, I M F}$ values, which started at around 11:30 UT and ended at around 18:10 UT on 8 September 2017 (red curve in panel a of Figure 1), the GNSS receiver located at SANAE IV base recorded weak/moderate 
amplitude scintillations affecting several satellites in view (panels $\mathrm{c}$ and $\mathrm{d}$ of Figure 2). The southward excursion of the $B_{\mathrm{z}, \mathrm{IMF}}$ component led to the equatorward expansion of the auroral oval due to an increased magnetospheric convection, encompassing SANAE IV station within the auroral oval.

To confirm this hypothesis, we compared corresponding auroral radiance measurements with amplitude scintillations. Figure 4 shows polar-view maps covering all MLT (00:00-24:00) and $150^{\circ}\left|-190^{\circ}\right|$ AACGM Lat sector of southern hemisphere. Each map displays the auroral radiance at 12:22 UT (a), 13:06 UT (b), 14:04 UT (c), 14:47 UT (d), 15:47 UT (e) and 16:25 UT (f) on September 8. Such times were selected to investigate the ionospheric scenario in which amplitude scintillations were recorded at SANAE IV base. Each map displays the auroral oval boundary location (red dashed contours), as retrieved from the auroral radiance data, and the projection to $350 \mathrm{~km}$ of altitude of the amplitude scintillations exceeding 0.1 (magenta diamonds), recorded during the DMSP passage. The projection to $350 \mathrm{~km}$ of altitude of all the $\sigma_{\varphi}$ values with an elevation angle $\alpha=30^{\circ}$ (purple circles) were reported to identify the field of view of the GNSS receiver along the DMSP track. This enables the comparison between the field of view of the GNSS receiver and the location of the auroral oval.
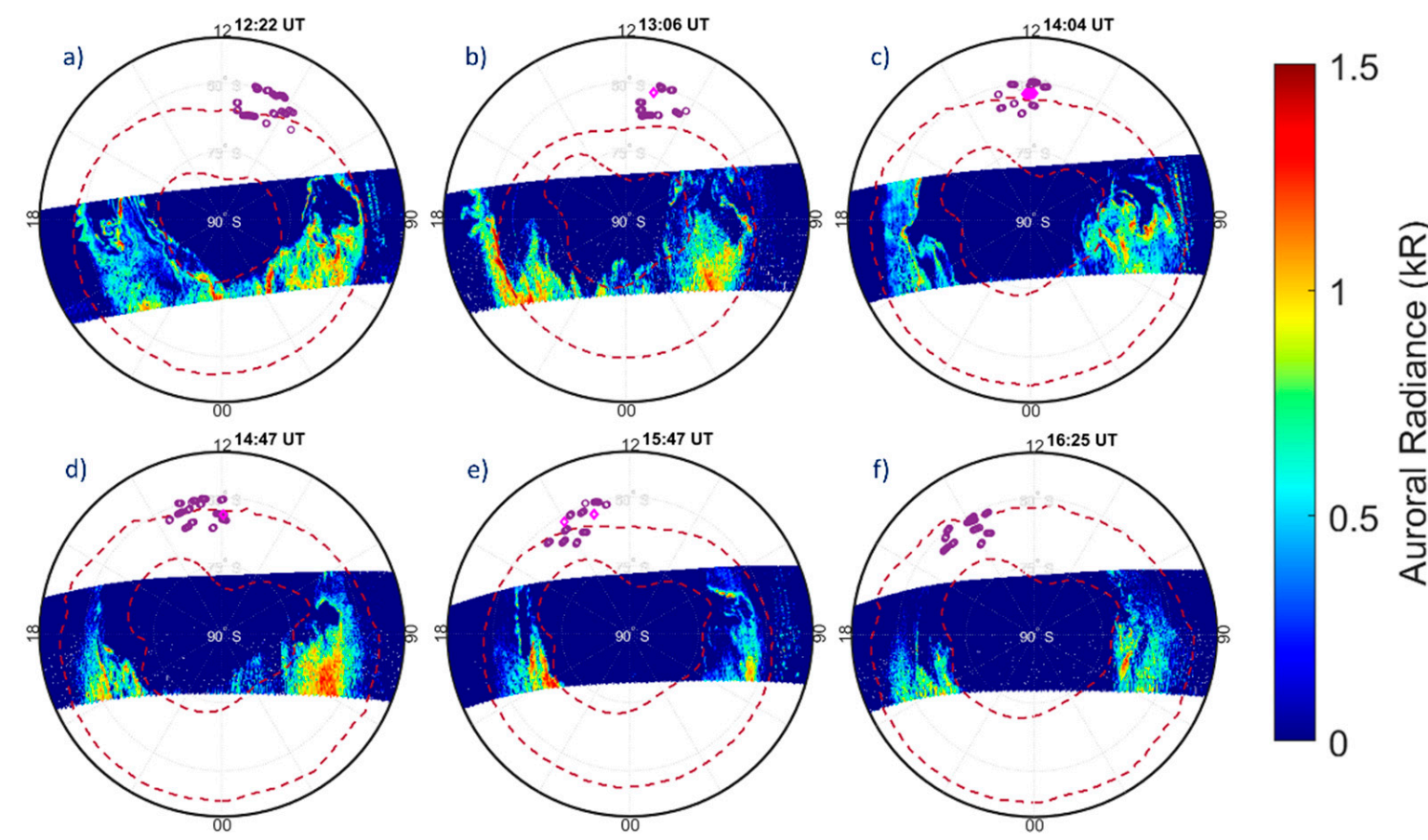

Figure 4. Polar-view maps in AACGM latitude and MLT of the austral auroral radiance as measured by SSUSI instrument in the LBHL band at 12:22 UT (a), 13:06 UT (b), 14:04 UT (c), 14:47 UT (d), 15:47 UT (e) and 16:25 UT (f) on 8 September 2017. Each map also reports the auroral oval boundary location (red dashed contours), as retrieved from the auroral radiance data, the amplitude scintillations greater than $0.1\left(S_{4}\right.$, magenta diamonds), recorded at SANAE IV base during the DMSP passage, and all the $\sigma_{\varphi}$ values having elevation angle $\alpha=30^{\circ}$ (purple circles). Scintillation data were projected to $350 \mathrm{~km}$ altitude. Each map covers 00:00-24:00 MLT and $150^{\circ} \mathrm{I}-190^{\circ}$ I AACGM Lat, the magnetic noon/midnight is at the top/bottom.

Although the observed scintillation is not collocated with the radiance measurements, the observation of the location of the field of view of the GNSS receiver (purple circles) with reference to the equatorward auroral oval boundary [44,45] (red dashed contours) shows that amplitude scintillations occurred in the ionospheric cusp. From the literature it is well-known that, in this region, the interaction between polar cap patches and cusp auroral dynamics can trigger strong GNSS phase scintillations [8,31,58,59]. Indeed, between 12:30 and 16:30 UT, the receiver located at SANAE IV base recorded phase scintillations up to $\sim 1.0 \mathrm{rad}$ (Figure 2c). This means that irregularities of spatial scale in the range of kilometers (or even more) $[3,60]$ were in the field of view of the receiver. In addition, the recording by 
GNSS receiver of both phase and amplitude scintillations suggests that significant plasma irregularities were present at all scales. These irregularities could be the consequence of density gradients due to the development of Gradient Drift Instability (GDI), driven by field-aligned currents or due to flow shears, which are common in the auroral ionosphere. They also could be direct consequences of cusp dynamics, i.e., precipitation associated with filamentary Field Aligned Currents (FAC) [61]. All of these processes can be responsible for the generation of large-scale inhomogeneities that provide a background on which small-scale instabilities can develop [62,63].

A corroboration of the presence of plasma fragmentation comes from maps in Figure 5, which display TEC data as a function of AACGM Lat and MLT, with a spatial resolution of $1^{\circ}$ AACGM Lat $x 4$ min MLT. Each map shows TEC data collected every 30 min following the time shown at the top of each map with the projection to $350 \mathrm{~km}$ of altitude of all the $\sigma_{\varphi}$ values having elevation angle $\alpha=30^{\circ}$ (purple circles) recorded in the same time interval as the TEC data by the GNSS receiver at SANAE IV. All maps show a clear signature of a Storm Enhanced Density (SED; see, e.g., References [64,65]) plume extending to a Tongue of Ionization (TOI; see, e.g., References [66-70]). Therefore, in the regions enclosed in the field of view of the GNSS receiver, TEC values appear generally higher than elsewhere, with TEC values exceeding $20 \mathrm{TECu}$ (see also Figure $2 \mathrm{a}$ ). In addition, such regions were characterized by irregular distributions of electron density, as highlighted by TEC values of different intensity for adjacent regions (Figure 5). This scenario suggests the presence of a local variability in the plasma dynamics, where intense and spatially localized density gradients exist, favouring the observed scintillation.
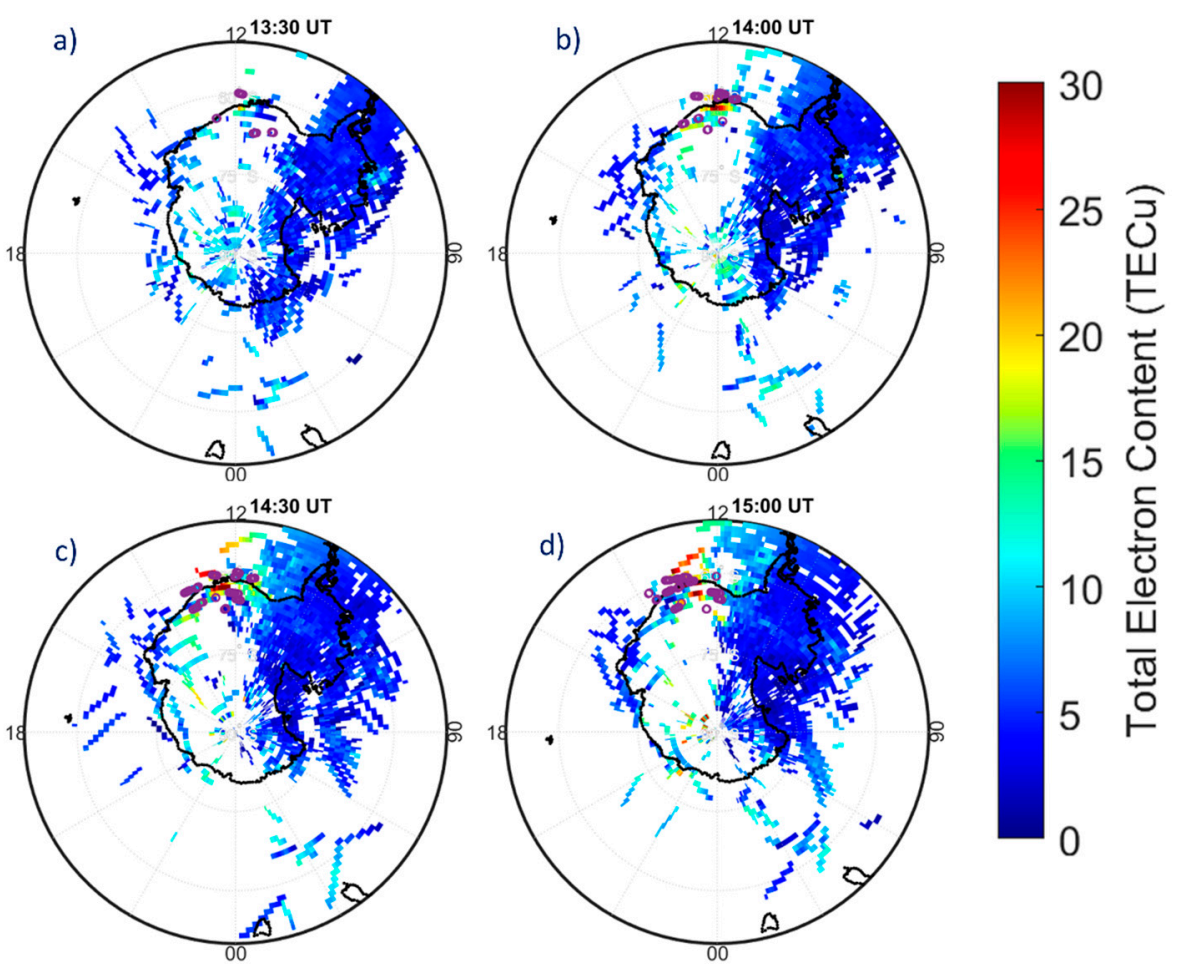

Figure 5. Polar-view maps in AACGM latitude and MLT, with spatial resolution of $1^{\circ}$ MLat $x 4$ min MLT, of the Total Electron Content (TEC) at 13:30 UT (a), 14:00 UT (b), 14:30 UT (c) and 15:00 UT (d) on 8 September 2017. Each map shows vertical TEC data collected in the $30 \mathrm{~min}$ following the time shown at the top of each map with the projection to $350 \mathrm{~km}$ of altitude of all the $\sigma_{\varphi}$ values having elevation angle $\alpha=30^{\circ}$ (purple circles) recorded at SANAE IV in the same time interval as the TEC data. In each map, that covers 00:00-24:00 MLT and $150^{\circ}|-| 90^{\circ} \mid$ AACGM Lat, the magnetic noon/midnight is at the top/bottom. 
To reveal the position of the magnetic observatory with respect to the auroral electrojet current system, observations of the ground geomagnetic field are provided. Figure 6 reports the variation of the values of the magnetic field along the $H$ and $Z$ components recorded at the ground magnetic observatory (SNA) located in SANAE IV base. These two magnetic components permit us to reveal the location of the magnetic observatory relative to the auroral electrojet current systems during the selected day. The $H$ component of the magnetic field, which points toward magnetic north, decreases in the presence of an ionospheric horizontal current flowing westwards and increases in the case of a current flowing eastwards. This means that according to the $H$ component values assumed during the day, the magnetometer station at SANAE IV base is in the southern hemisphere auroral zone in two different time intervals, i.e., between 00:00 and 07:00 UT and between 13:00 and 24:00 UT. On the other hand, during the time interval 07:00-13:00 UT, it is outside the auroral oval. When the magnetometer station is inside the auroral oval it is located initially underneath the westward auroral electrojet, in correspondence with negative values of the perturbation in the $H$ component, and subsequently underneath the eastward auroral electrojet, in correspondence with positive values of the perturbation in the $H$ component. At last, the $\mathrm{Z}$ component permits to estimate the position of the station with respect to the peak of the electrojet. Indeed, when a ground station is located directly below the peak of the electrojet, most of the ground perturbation is recorded in the $H$ component with minimal or no perturbation along the $Z$ component. When, as in the case considered here, there is a magnetic perturbation in both the $H$ and $Z$ components, this means that the ground station is located either poleward or equatorward of the electrojet peak but it is still underneath the bulk of it.
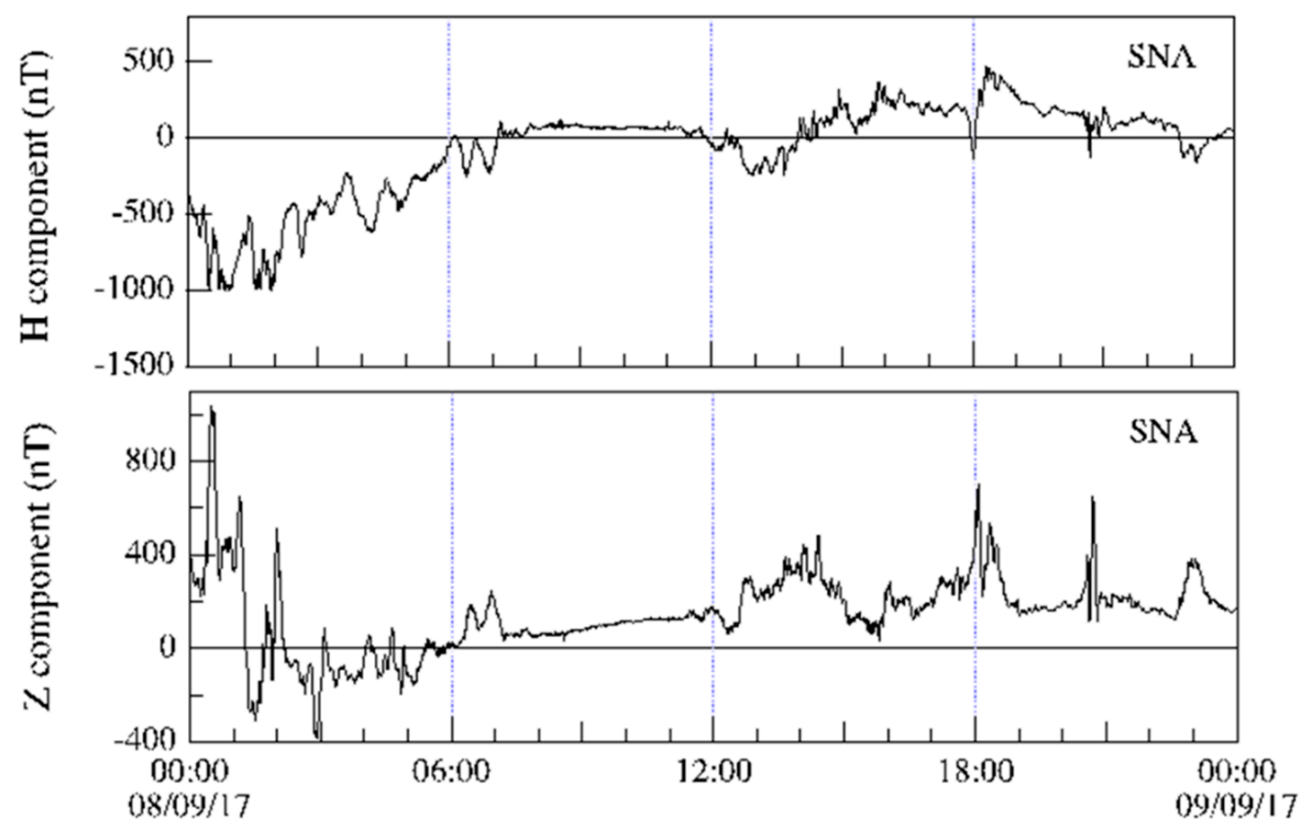

UT

Figure 6. $H$ and $Z$ magnetic field components recorded at SNA magnetic station located in SANAE IV base on 8 September 2017.

Between about 13:30 and 15:30 UT, corresponding to the time interval in which the GNSS receiver recorded amplitude scintillations (Figure 2d), the magnetic station crosses the two different auroral electrojets moving from the westward to the eastward one, which is a clear signature of a transition from dawn to dusk side of the cusp. In fact, between about 07:30 and 11:30 UT, that is when $B_{z, I M F}$ was around zero (see red curve in panel a of Figure 1), the variation in the Earth's magnetic field recorded at SNA was almost zero, as expected from a sub-auroral station under geomagnetically quiet conditions. On the 
contrary, when $B_{\mathrm{z}, \mathrm{IMF}}$ turned strongly southward at about 11:45 UT (red curve in panel a of Figure 1), and the auroral oval and the ionospheric convection cell expanded equatorward, SNA became a cusp/auroral station, and intense fluctuations of geomagnetic field were observed. Such transition, characterized by strong magnetic field variations, together with the observed TEC values ( $>30 \mathrm{TECu}$ ) greater than those generally recorded in quiet conditions $(<20 \mathrm{TECu})$, leads to speculate about the setting, in this region, of a very structured FAC activity, where filamentary currents accompany an increase in electron precipitation. The presence of filamentary FACs, often associated with multifractal and turbulent behaviors of magnetic field variations (e.g., Reference [71]), could induce local electric field gradients able to alter the amplitude of an electromagnetic signal which crosses such region. This scenario agrees with Meziane et al. [72] who found the cusp as the sole GNSS scintillation hotspot.

In addition, it is possible to suppose the presence of different plasma regimes in which irregularities of the order of the first Fresnel radius or even below, can form, which is compatible with the observed amplitude scintillations. Figure 7 shows further evidence that support this hypothesis. In detail, each map in Figure 7 shows the isocontours of the ionospheric potential (red = positive, blue = negative potential) as derived from SuperDARN convection velocity measurements and extended to the whole auroral region by means of an empirical model $[73,74]$. Moreover, the locations of actual SuperDARN measurements (black squares) recorded in the two minutes following the time shown at the top of each map are also shown. Each map also reports the projection to $350 \mathrm{~km}$ of altitude of all the $\sigma_{\varphi}$ values recorded by SNA0 with elevation angle $\alpha=30^{\circ}$ (purple circles) in the same time interval as for SuperDARN observations. All the maps show that between 13:38 and 13:44 UT the overall convection pattern in the Southern Hemisphere is driven by the huge and continuous negative values of $B_{\mathrm{z}, \mathrm{IMF}}$ with convection cells tilted towards dawn because of the positive $B_{\mathrm{y}, \mathrm{IMF}}$ values (panel a of Figure 1, red and blue curve, respectively). In addition, the location of the GNSS receiver's field of view (purple circles) with respect to the configuration of the ionospheric potential cells and to the SuperDARN measurements (black squares) suggests that amplitude scintillations occurred at the cusp and close to the ionospheric regions in which SuperDARN recorded echoes back from the ionosphere. It is worth mentioning that SuperDARN echoes originate when a transmitted signal encounters plasma density irregularities of spatial scale in the order of tens of meters, mainly caused by the GDI. It is well-known that, when large-scale gradients (of the order of kilometers or tens of kilometers) occur in the high latitude ionosphere, GDI generates irregularities in cascade down to scales of meters or even below (e.g., Reference [75]). Therefore, irregularities causing amplitude scintillation in the L-band Fresnel scale can be co-located with decameter irregularities causing HF backscatter (see also Reference [22]). This observation further confirms the presence of small-scale ionospheric irregularities.

\subsection{SANAE: Phase Fluctuations without Amplitude Scintillations}

Between 00:00 and 06:00 UT, around 18:00 UT and between 20:00 and 21:00 UT on 8 September the GNSS receiver located at SANAE IV recorded moderate/strong $\sigma_{\varphi}$ levels with very low $\left(S_{4}<0.1\right)$ or no amplitude scintillation events (Figure 2, panel c and $\mathrm{d}$, respectively). By comparing the phase fluctuations that occurred between 00:00 and 06:00 UT with the magnetic field observations recorded at the same time by the magnetometer co-located with the GNSS receiver (Figure 6), it can be seen that such events occurred when the station is located either poleward or equatorward of the electrojet peak. Indeed, the peaks of $\sigma_{\varphi}$ are well in agreement with the peaks of the $Z$ magnetic field component. This means that the phase fluctuations of the recorded GNSS signals seem to occur when the station is located underneath the edge of the electrojet, i.e., the region where instability and turbulence processes are more likely to occur [63,76-80]. Thus, the comparison between $\sigma_{\varphi}$ variations and geomagnetic observations suggests that the observed fluctuations have been caused by variations in plasma dynamics and have, therefore, a refractive nature. 

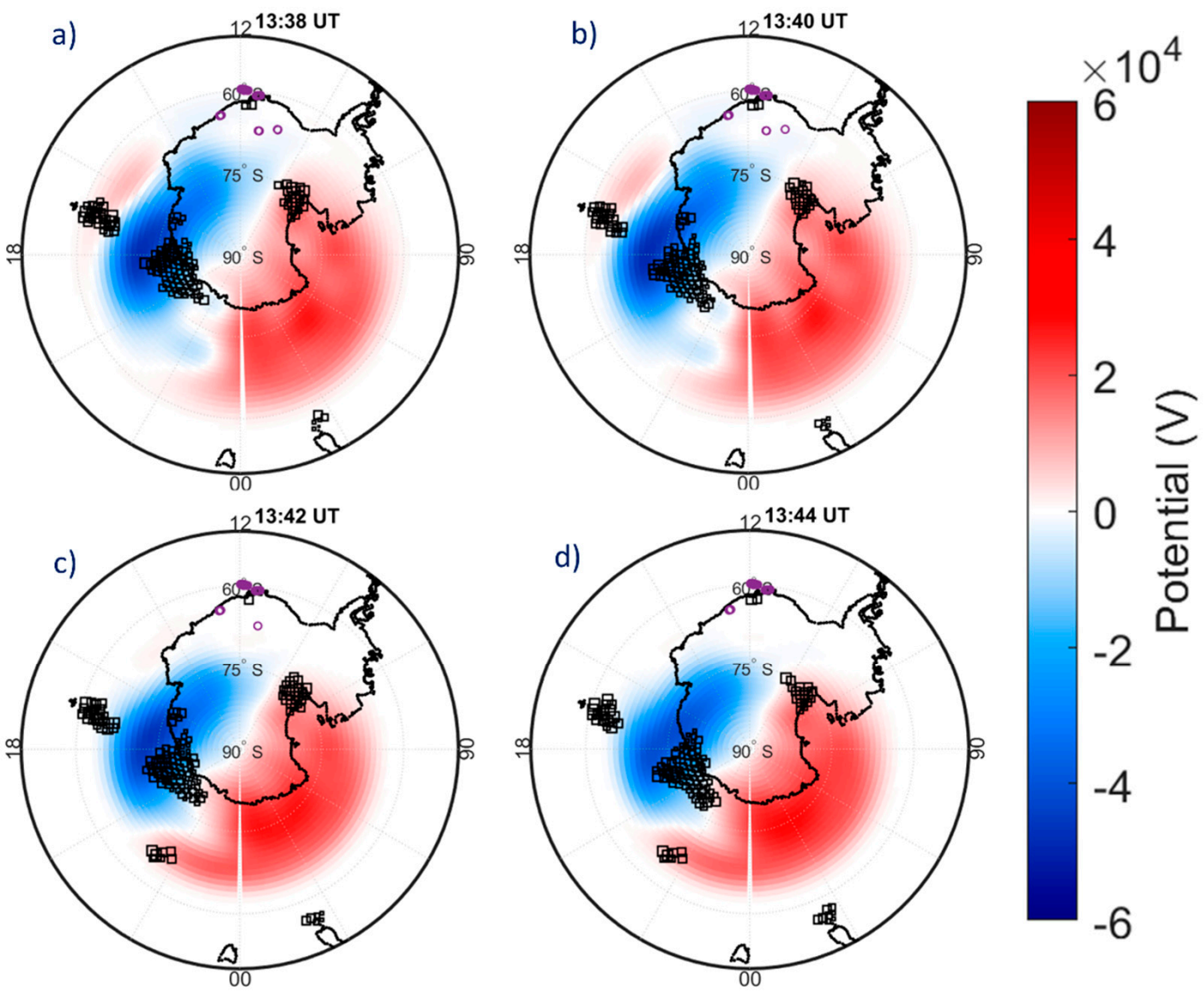

Figure 7. Polar-view maps in AACGM latitude and MLT of SuperDARN observations at 13:38 UT (a), 13:40 UT (b), 13:42 UT (c) and 13:44 UT (d) on 8 September 2017. Each map shows the isocontours of the ionospheric potential (red=positive, blue=negative potential) and SuperDARN measurements (black squares) recorded in the two minutes following the time shown at the top of each map. In each map the projection to $350 \mathrm{~km}$ of altitude of all the $\sigma_{\varphi}$ values recorded by SNA0, with elevation angle $\alpha=30^{\circ}$ (purple circles), in the same time interval as for SuperDARN observations are also shown. In each map, which covers 00:00-24:00 MLT and 150 I-190 I AACGM Lat, the magnetic noon/midnight is at the top/bottom.

In order to confirm such a hypothesis, we compared the $\sigma_{\varphi}$ variations with the corresponding auroral radiance measurements. Likewise, as shown in Figure 4, Figure 8 shows polar-view maps of the auroral radiance as measured by SSUSI at 01:10 UT (a), 18:07 UT (b) and 20:46 UT (c) on September 8. Such times were selected to investigate the ionospheric background in which the GNSS receiver at SANAE IV base recorded phase fluctuations without amplitude scintillations. The maps display also the auroral oval boundaries location (red dashed contours) as retrieved from the auroral radiance data and the projection to $350 \mathrm{~km}$ of altitude of the $\sigma_{\varphi}$ greater than $0.25 \mathrm{rad}$ (magenta diamonds), recorded during the DMSP passage. In each map, the projection to $350 \mathrm{~km}$ of altitude of all the $\sigma_{\varphi}$ values with an elevation angle $\alpha=30^{\circ}$ (purple circles) were reported to identify the field of view of the GNSS receiver along the DMSP track. This enables a comparative analysis to show the correlation between phase fluctuations and particle precipitation into the auroral oval. 

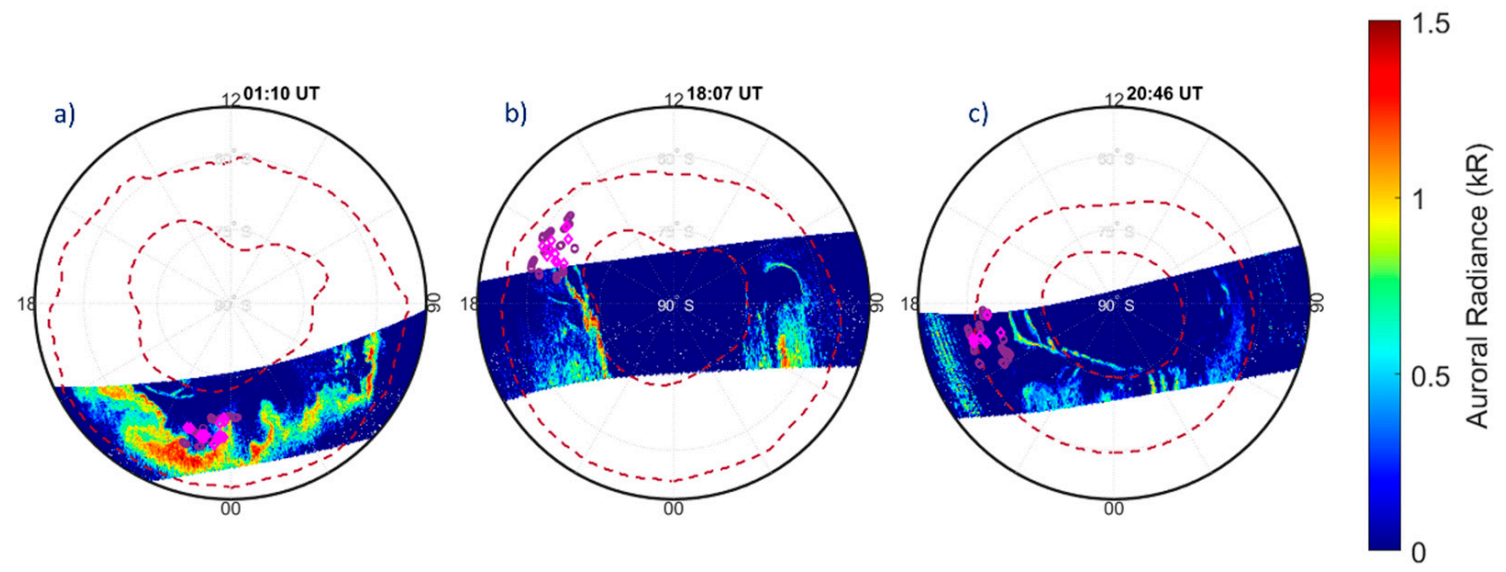

Figure 8. Polar-view maps in AACGM latitude and MLT of the austral auroral radiance as measured by SSUSI instrument in the LBHL band at 01:10 UT (a), 18:07 UT (b) and 20:46 UT (c) on 8 September 2017. Each map also reports the auroral oval boundaries location (red dashed contours), as retrieved from the auroral radiance data, the $\sigma_{\varphi}$ greater than 0.25 rad (magenta diamonds), recorded at SANAE IV base during the DMSP passage, and all the $\sigma_{\varphi}$ values having elevation angle $\alpha=30^{\circ}$ (purple circles). GNSS data were projected to $350 \mathrm{~km}$ altitude. Each map covers 00:00-24:00 MLT and $\left|50^{\circ}\right|-\left|90^{\circ}\right|$ AACGM Lat, the magnetic noon/midnight is at the top/bottom.

All maps show that during the investigated periods, the GNSS receiver's field of view (purple circles) was inside the auroral oval. From panel a, it is clear that moderate/strong $\sigma_{\varphi}$ variations (magenta diamonds) occurred near regions characterized by high values of auroral radiance. This suggests the crucial role of the auroral precipitation in creating electron density gradients of a scale size above the Fresnel's scale for L-band signals, resulting in mostly refractive effects on the phase. Furthermore, the position of the receiver field of view at 01:10 UT (panel a) suggests that the observed events may have been caused by auroral blobs formed when polar cap patches enter the nightside auroral region [14,81,82]. The presence of refractive effects at L-band may be due to the combination of such patches with the observed precipitation, which is the main source of localized and strong E-field with magnitudes significant enough to drive instabilities.

The combination of observations from diverse instruments suggests that, close to the boundaries of the auroral electrojets (Figure 6) or along the edge of the auroral oval (Figure 8), it is possible to suppose the existence of irregularities of the order of the first Fresnel L-band. Indeed, when the GNSS receiver recorded phase fluctuations without amplitude scintillations SuperDARN recorded echoes back from the ionosphere (not shown) near/inside the receiver's field of view, confirming the presence of irregularities with a spatial scale of the order of tens of meters [47]. According to the results described in the previous section, we would have expected to also observe amplitude scintillations in these regions, triggered by the irregularities of scale sizes up to the first Fresnel radius, including those revealed by SuperDARN. Our results suggest that the lack of amplitude scintillation can be ascribed to the recording of TEC values that are lower during phase fluctuations $(<12 \mathrm{TECu}$, Figure 2a) than during both amplitude and phase scintillations ( $>20 \mathrm{TECu}$, Figure 2a). In fact, low TEC values would imply that the energy associated with the electric field gradient corresponding to the observed electron density irregularities was not sufficient to trigger amplitude scintillations. Since the electric field gradients depends on both TEC gradients and magnetic field variations, we suggest that electric field variations may cause amplitude scintillations. Indeed, the amplitude of a signal carries the information about the energy of the system in which it flows through. So, if the signal crosses a region in which an intense energy variation exists, the signal's statistical parameters (i.e., autocorrelation) and, hence, its amplitude will be modified proportional to the intensity of the crossed energy variation [83]. Such link between amplitude scintillations and electric field gradients is similar to the driving mechanism behind the low-latitude occurrence of $S_{4}>0.1[84,85]$. 


\subsection{Concordia: Amplitude and Phase Scintillations}

The variations of scintillation parameters recorded on 8 September 2017, by the receiver located at Concordia (Figure 3) mainly occurred concurrent with negative excursions of the $B_{Z, I M F}$ (red curve in panel a of Figure 1). This condition led to a large amount of particles precipitating in the high-latitude ionosphere, as confirmed by Figure 9.

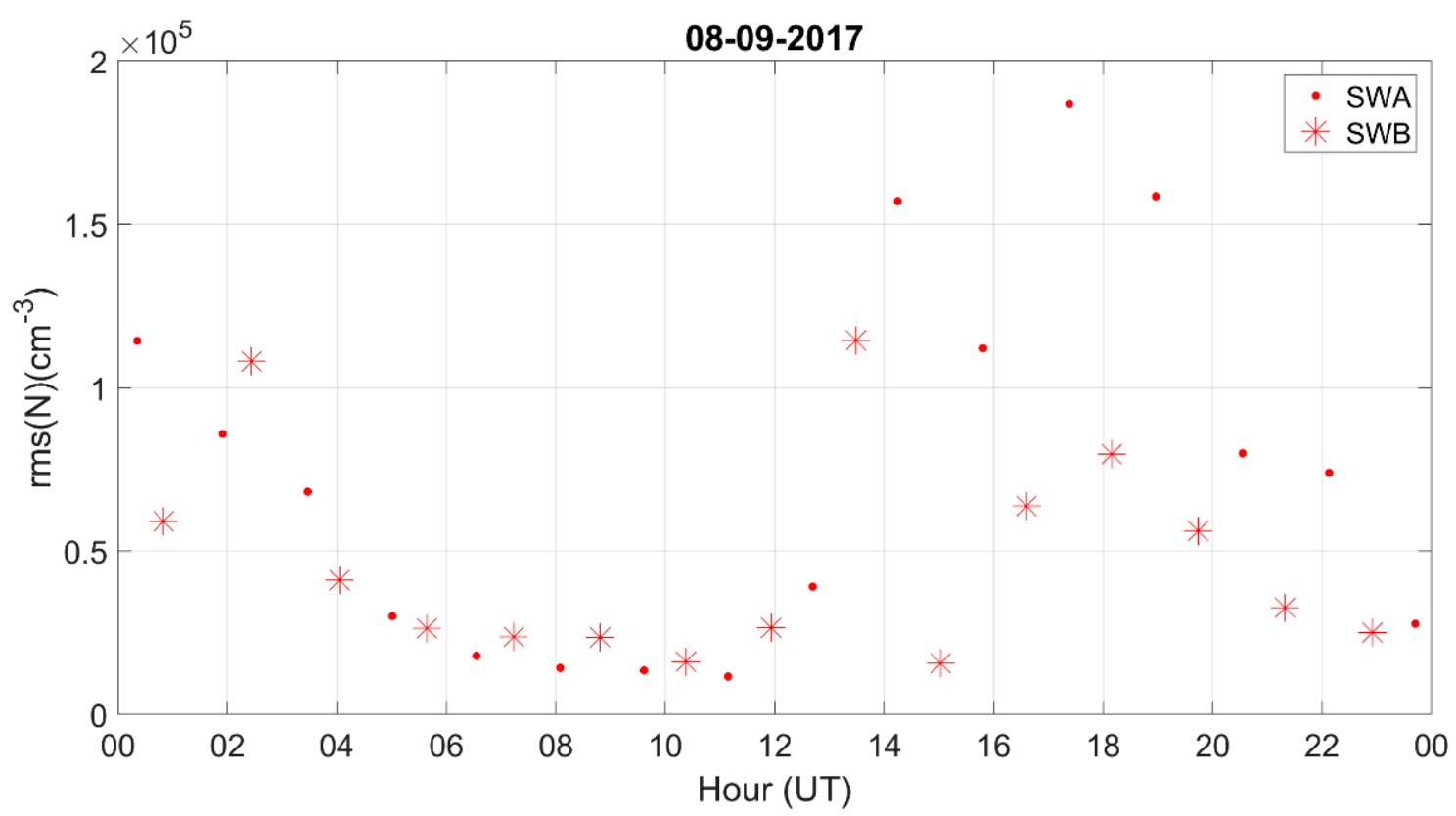

Figure 9. Electron density root mean square $(r m s)$ by Swarm A (dots) and Swarm B (stars) on 8 September 2017, in the Southern Hemisphere. The AACGM latitude ranges between $70^{\circ}$ and $90^{\circ} \mathrm{S}$.

This figure displays the variations of the electron density root mean square (rms) by Swarm A (SWA, dots) and Swarm B (SWB, stars). Specifically, rms is calculated for each electron density time series related to a polar crossing of each Swarm satellite over an area spanning $70^{\circ}$ AACGM latitude. By comparing electron density rms (Figure 9) and $B_{\text {z,IMF }}$ (Figure 1, red curve in panel a) variations, we see that, between 00:00 and 02:30 UT and between 12:00 and 17:30 UT, i.e., when $B_{z, I M F}$ was southward, huge increases in the rms values observed by both satellites occurred. Conversely, when $B_{Z, I M F}$ was northward or near null, the $r m s$ intensity decreased. Hence, since $r m s$ variations essentially trace the $B_{Z, I M F}$ profile, it is possible to relate the electron density increases highlighted by increases in $r m s$ with the particle precipitation caused by southward $B_{z, I M F}$. Since electron density increases suggests the presence of patches [86-88], we investigated the behavior of PCP flag over the Southern Hemisphere during the analyzed geomagnetic storm.

In fact, contrary to the case of the GNSS receiver located at SANAE IV base, whose field of view looks at latitudes not covered by the PCP flag, at the magnetic latitudes covered by the receiver's field of view at Concordia we can take advantage of the information provided by this index. Figure 10 shows the PCP flag estimated by Swarm A (red) and Swarm B (blue) measurements. Specifically, each map displays PCP flag values different from zero (i.e., presence of polar cap patches), collected by both Swarm satellites in the time interval shown on the top of each panel, and the projection to $350 \mathrm{~km}$ of altitude of all the concurring $\sigma_{\varphi}$ values having elevation angle $\alpha=30^{\circ}$ (purple circles) recorded by the GNSS receiver at Concordia. This enables a comparative investigation between the occurrences of patches and GNSS scintillation. The comparison between maps in Figure 10 and the $B_{z, I M F}$ trend (red curve in panel a of Figure 1) shows that during southward $B_{Z, I M F}$ the values of the PCP flag confirm the presence of patches. In addition, Figure 10 shows that Swarm satellites detected patches both close to and inside the GNSS field of 
view during scintillation events (see panels $\mathrm{c}$ and $\mathrm{d}$ of Figure 3), thus suggesting that PCP could have caused the corruption of the corresponding GNSS signals $[11,13]$.
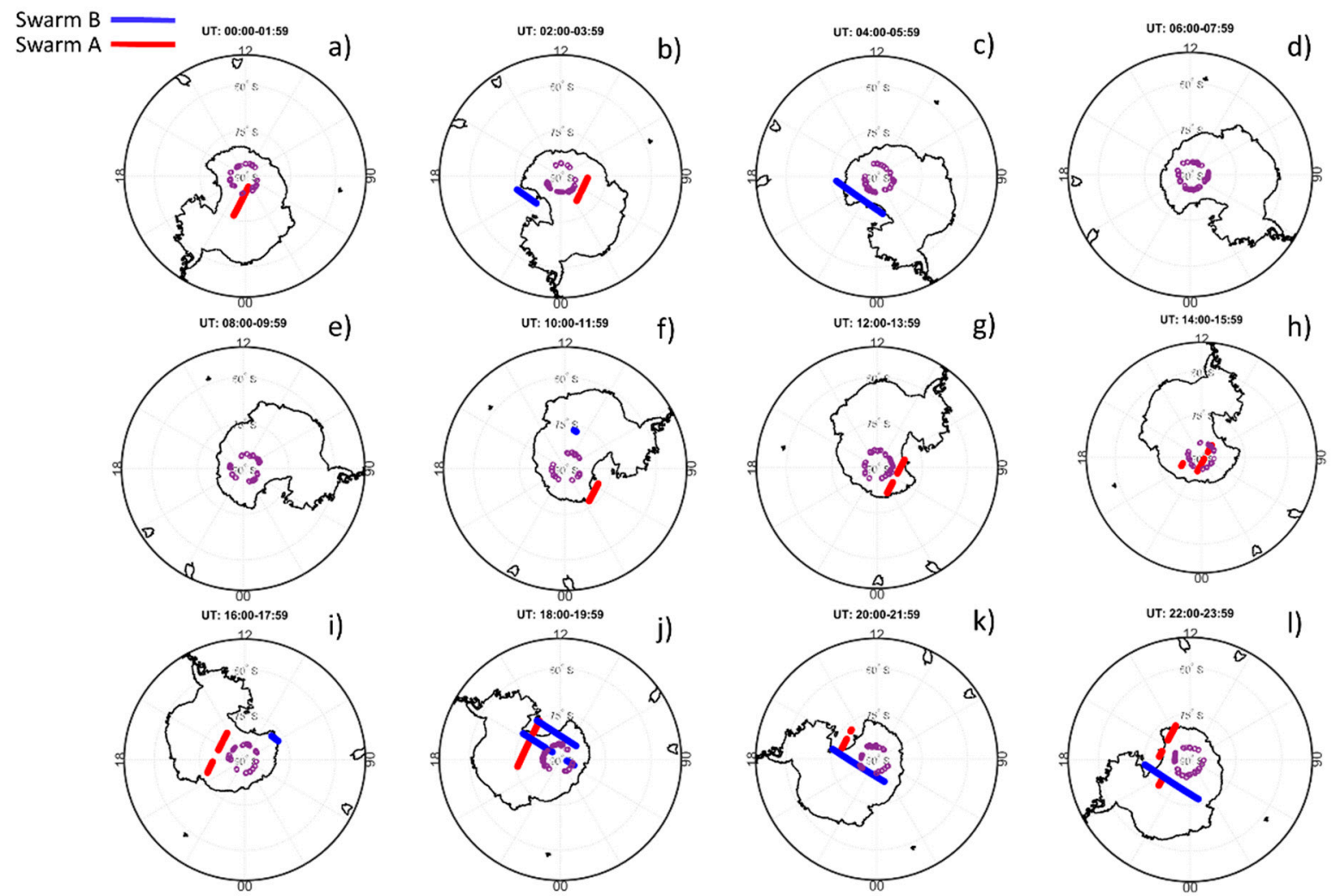

Figure 10. Polar-view maps in AACGM latitude and MLT coordinates displaying the different from zero values of the PCP flag estimated by Swarm A (red) and Swarm B (blue) data on 8 September 2017. In each map the projection to $350 \mathrm{~km}$ of altitude of all the $\sigma_{\varphi}$ values recorded by the GNSS receiver located at Concordia, which have elevation angle $\alpha=30^{\circ}$ (purple circles) are also shown to highlight the receiver's field of view. Each map reports the observations collected in the time interval displayed on the top of each map. Each map covers 00:00-24:00 MLT and $150^{\circ}|-| 90^{\circ} \mid$ AACGM Lat, the magnetic noon/midnight is at the top/bottom.

The variations of scintillation parameters as shown in Figure 3 further support this hypothesis. Indeed, scintillations (panels $\mathrm{c}$ and d) recorded at Concordia between 00:00 and 04:00 UT and between 12:00 and 20:00 UT on September 8 occurred together with high TEC values (panel a) and intense ROT variations (panel b). According to Wernik et al. [42] and Alfonsi et al. [8], this suggests that the investigated regions were populated by irregularities of largely varying spatial scales. In fact, the relation between ROT and Nyquist period [43] allows retrieving the irregularities scale length involved in scintillations [8]. So, since at high latitudes experimental evidence shows that plasma convection velocities span a range between $100 \mathrm{~m} / \mathrm{s}$ and $1 \mathrm{~km} / \mathrm{s}$ [89], the relative irregularities scale length, sampled by ROT, varies from a few kilometers to tens of kilometers [60]. Such spatial scales correspond to the typical PCP dimensions [90-92] that in L-band scintillations identify large-scale irregularities with respect to the small-scales associated with the first Fresnel radius [3].

The fact that the GNSS receiver recorded amplitude and phase scintillations suggests that even smaller-scale irregularities populated the investigated region, probably caused by the strong variability of plasma dynamics induced by particle precipitation. Indeed, the comparison between scintillation indices (c and d panels in Figure 3) and electron density rms variations (Figure 9) shows that the observed scintillations occurred in correspondence with sharp and sudden variations of the calculated rms. Since $r m s$ is an estimation of the variation of the electron density, its sharp and sudden increases/decreases between two consecutive orbits suggest a high variability of plasma dynamics. In addition, since the 
electron density rms variations occurred simultaneously to the greatest ROT excursions recorded by the GNSS receiver during the day (Figure $3 b$ ), it is possible to say that the observed scintillation may be linked to sudden changes in plasma dynamics. In fact, ROT supplies information about the TEC rate of change being defined as the TEC first time derivative (providing ROT values in units of total electron content unit over one minute, $[\mathrm{TECu} / \mathrm{min}])$. Since ROT provides information on plasma dynamics, it allows associating the observed scintillations with variations in plasma dynamics. In this scenario, it is reasonable to argue the presence of ionospheric irregularities.

Maps in Figure 11 confirm this hypothesis. Specifically, each map displays TEC data as a function of AACGM latitude and MLT, with a spatial resolution of $1^{\circ}$ AACGM Lat $x$ 4 min MLT. Each map shows TEC data collected every $30 \mathrm{~min}$ following the time shown at the top of each map with the projection to $350 \mathrm{~km}$ of altitude of all the $\sigma_{\varphi}$ values having elevation angle $\alpha=30^{\circ}$ (purple circles) recorded in the same time interval as the TEC data by the GNSS receiver at Concordia. The variability of TEC in adjacent regions, including those regions enclosed in the field of view of the GNSS receiver (highlighted by purple circles), indicates that several irregularities populated the polar cap ionosphere. In addition, inside the receiver's field of view, TEC values appear generally higher than those in the surrounding areas. This scenario suggests the presence of a locally large variability of the plasma dynamics that may have favored the fragmentation of the PCP in irregularities of the order of the first Fresnel radius.
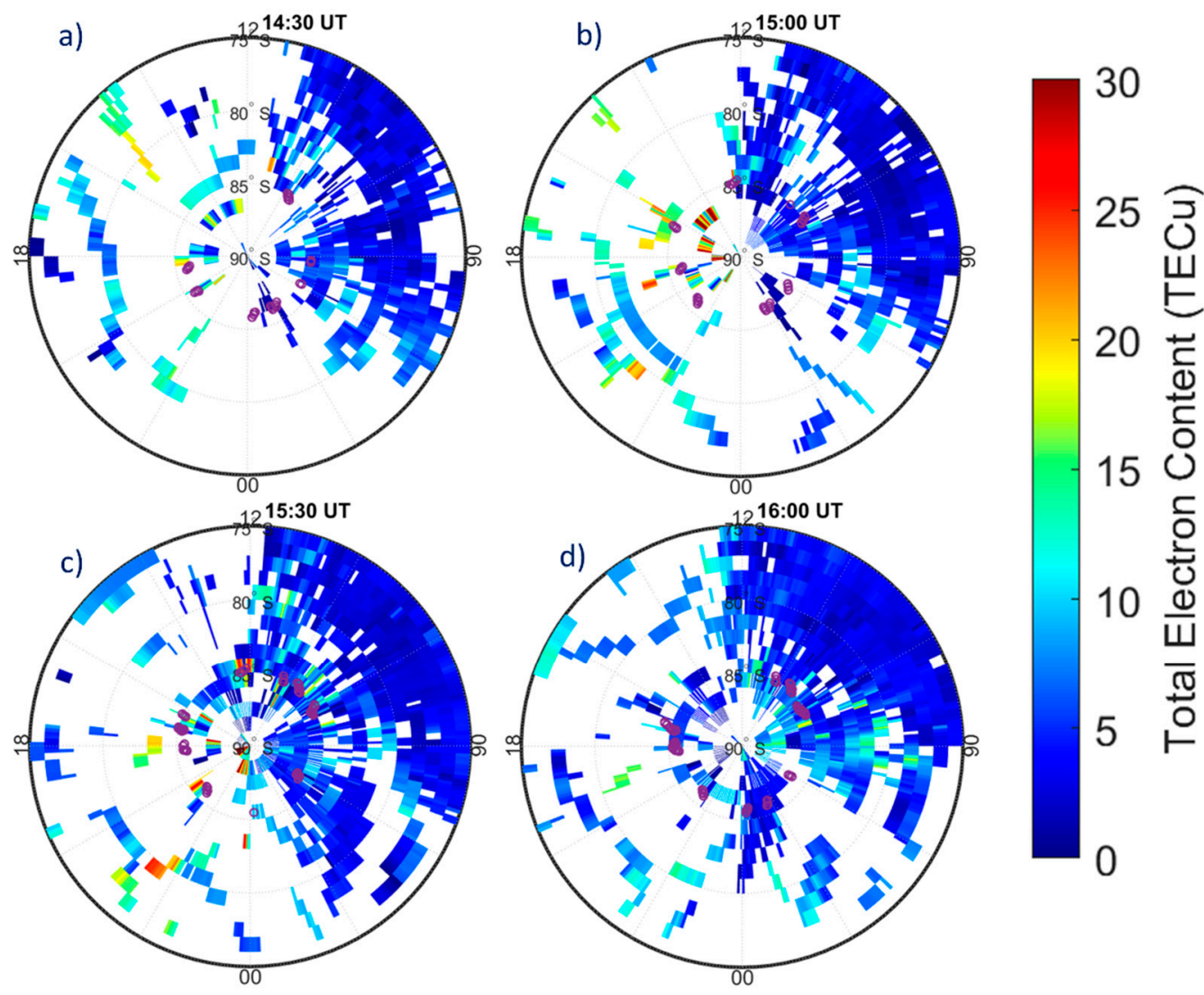

Figure 11. Polar-view maps in AACGM latitude and MLT, with spatial resolution of $1^{\circ}$ MLat $x 4$ min MLT, of the Total Electron Content (TEC) at 14:30 UT (a), 15:00 UT (b), 15:30 UT (c) and 16:00 UT (d) on 8 September 2017. Each map shows TEC data collected in the $30 \mathrm{~min}$ following the time shown at the top of each map with the projection to $350 \mathrm{~km}$ of altitude of all the $\sigma_{\varphi}$ values having elevation angle $\alpha=30^{\circ}$ (purple circles) recorded at Concordia in the same time interval as the TEC data. In each map, that covers 00:00-24:00 MLT and $175^{\circ}\left|-190^{\circ}\right|$ AACGM Lat, the magnetic noon/midnight is at the top/bottom. 
Figure 12 reports the variations in the $H$ and $Z$ components of the magnetic field recorded at the DMC ground magnetic station located at Concordia. As in the case of SNA, these two magnetic components help reveal the location of the DMC magnetic station with respect to the auroral electrojet current systems during the selected day. The station is always located inside the auroral oval, moving from 22:00 to around 09:00 UT underneath the auroral electrojet eastward and from 09:00 and 22:00 UT underneath the westward one. According to the values of the $\mathrm{Z}$ component, DMC magnetic station is underneath the bulk of the current only in the time interval from 15:00 to 20:00 UT, when the values of the $Z$ component are close to zero.

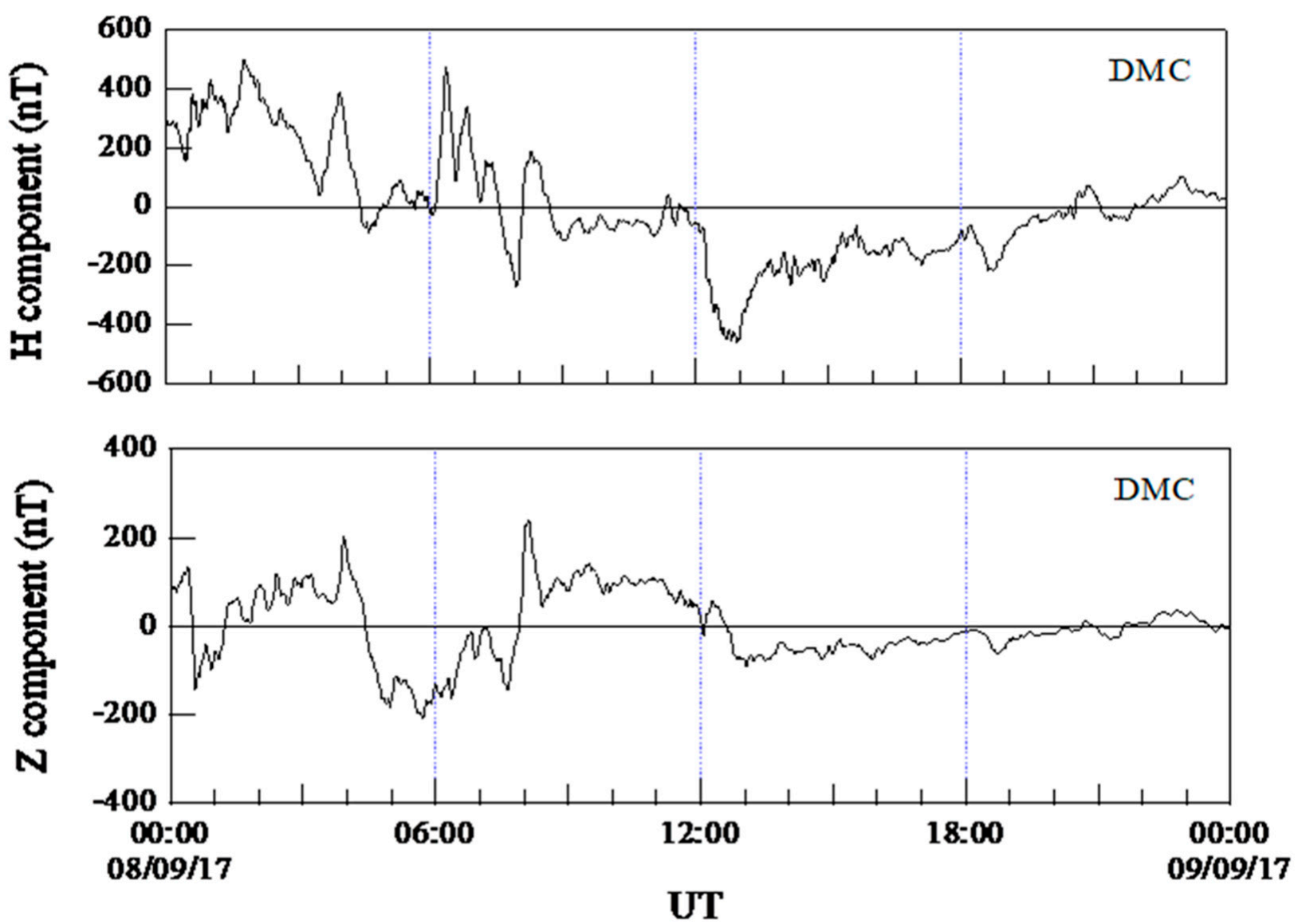

Figure 12. $H$ and $Z$ magnetic field components recorded at DMC magnetic station at Concordia on 8 September 2017.

Finally, Figure 13 shows the isocontours of the ionospheric potential (red = positive; blue = negative potential) derived from SuperDARN measurements along with the location of measurements themselves (black squares) recorded in the two minutes following the time shown at the top of each map. In each map the projection to $350 \mathrm{~km}$ of altitude of all the $\sigma_{\varphi}$ values, which have elevation angle $\alpha=30^{\circ}$ (purple circles), recorded in the same time interval as for SuperDARN observations by the GNSS receiver at Concordia, are also shown. In all maps, the location of the GNSS receiver's field of view (purple circles) with respect to the configuration of the ionospheric potential cells suggests that amplitude scintillations occurred in the ionospheric region between the two convection cells. Such region is well-known to be characterized by fluid and magnetohydrodynamic turbulence in ionosphere or in magnetosphere, which map to the ionosphere [62,93,94], which is able to generate small-scale irregularities. In addition, inside the GNSS receiver's field of view (purple circles) SuperDARN recorded echoes back from the ionosphere, confirming the presence of irregularities whose spatial scale is well below the L-band Fresnel scale [47]. The higher level of phase scintillation than the amplitude scintillation at Concordia is due to the already mentioned detrending filtering issue [29]. Spogli et al. [29] report also an 
estimate of the plasma relative velocity ranging from 200 to $500 \mathrm{~m} / \mathrm{s}$, confirming the highly dynamic scenario in which phase and amplitude fluctuations were observed.
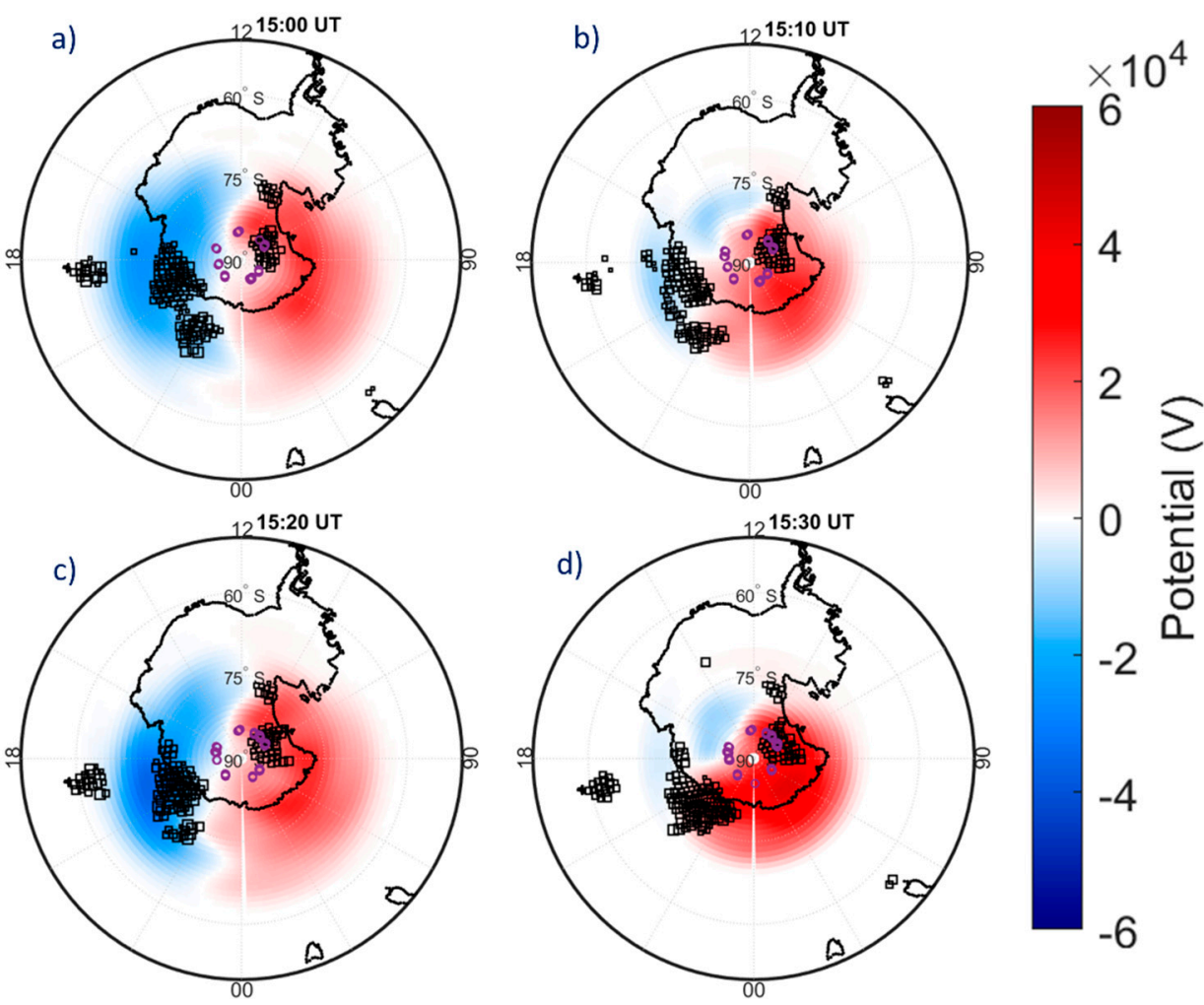

Figure 13. Polar-view maps in AACGM latitude and MLT of SuperDARN observations at 15:00 UT (a), 15:10 UT (b), 15:20 UT (c) and 15:30 UT (d) on 8 September 2017. Each map shows the isocontours of the ionospheric potential (red = positive, blue = negative potential) and the location of SuperDARN measurements (black squares) recorded in the two minutes following the time shown at the top of each map. In each map the projection to $350 \mathrm{~km}$ of altitude of all the $\sigma_{\varphi}$ values having elevation angle $\alpha=30^{\circ}$ (purple circles), recorded by the GNSS receiver at Concordia in the same time interval as for SuperDARN observations are also shown. In each map, which covers 00:00-24:00 MLT and $\left|50^{\circ}\right|-\left|90^{\circ}\right|$ AACGM Lat, the magnetic noon/midnight is at the top $/$ bottom.

\section{Summary and Concluding Remarks}

This paper investigates the high-latitude ionosphere dynamics in terms of irregularity formation triggered by the intense solar event of 8 September 2017. It adopts a multiobservation approach combining information from TEC spatial-temporal variation and scintillation parameters, with measurements acquired by the SSUSI instrument on board the DMSP satellites, SuperDARN, Swarm spacecraft and ground-based magnetometers.

The proposed investigation, together with the integration of the large variety of data used, allows for the collocation the observed amplitude and phase scintillations with a highly perturbed ionosphere characterized by strong variability of plasma dynamics and intense ionization. In this storm, indeed, the ionization enhancement due to the intense particle precipitation during periods of strong southward $B_{\mathrm{Z}, \mathrm{IMF}}$ is added to the ionization due to both flares and solar proton events with energies greater than $10 \mathrm{MeV}[52,53]$. Consequently, SED plume, TOI and PCP developed, as highlighted by both high TEC values and the electron density increases measured in situ by Swarm satellites. In addition, both the GNSS receivers located at SANAE IV and Concordia stations recorded vertical TEC values much higher than during quiet times, which exceeded $20 \mathrm{TECu}$, concurrent with amplitude and phase scintillation events. Such local vertical TEC increases induced a locally large variability of the plasma dynamics as confirmed by both the geomagnetic field variations, recorded at ground by magnetometers co-located with GNSS receivers, 
and the comparison among scintillation parameters, ROT and electron density variations measured in situ by Swarm satellites. Specifically, in the same time interval as for amplitude scintillations, both the magnetometers at SANAE IV and Concordia recorded simultaneous variations of both the $H$ and $Z$ components of the geomagnetic field, highlighting the quick succession inside the field of view of the GNSS receivers of ionospheric currents of varying intensity. In addition, in conjunction with moderate/intense phase and amplitude scintillations, large increases of electron density rms occurred simultaneously with the greatest ROT excursions. Since rms is an estimation of the mean value of the electron density and ROT supplies information about the TEC rate of change, the simultaneity among ROT excursion, electron density rms variation between two consecutive orbits and GNSS scintillations confirms the high variability of the plasma dynamics and the association of the observed scintillation with such variability.

The ionospheric scenario depicted by the proposed multi-observation approach results in an uneven electron density distribution. As shown in vertical TEC maps (Figures 5 and 11), several gradients populated the investigated regions, confirming the presence of plasma variability. The spatial scale size of irregularities detected in such maps is not small enough to justify the observed amplitude scintillation but the occurrence of echoes back from the ionosphere, recorded by SuperDARN in the field of view of GNSS receivers, confirms the presence of small-scale irregularities (on the order of tens of meters).

The investigation highlights that the existence of irregularities with a spatial scale of the order of the first Fresnel L-band radius or below is not a sufficient condition to trigger amplitude scintillation of GNSS signals. According to the understanding we gained from multi-instrument observations, the lack of amplitude scintillations can be attributed to the values of vertical TEC being lower during scintillation events affecting only the phase of GNSS signals ( $<12 \mathrm{TECu}$ ) than, at both sites, during phase and amplitude scintillation events (>20 TECu). Indeed, in agreement with both Carrano et al. [95] and Jin and Oksavik [41], we found that the most intense phase and amplitude fluctuations of the GNSS signals occurred in those regions characterized by intense vertical TEC gradients that occur only when the background TEC is on the order of $20 \mathrm{TECu}$. The latter, indeed, would ensure that the energy associated with the electric field gradients is sufficient to trigger amplitude scintillation at high latitudes. Our results suggest that a kind of "threshold" in the background density seems to exist, above which the amplitude scintillation is favored. However, this aspect deserves further investigations that we leave to future studies.

The high level of ionization recorded by both Swarm satellites and GNSS receivers, suggests that the lifetime of small-scale irregularities is greater than the time needed to the ionosphere to locally adjust the dynamics following an increase in conductivity. This observation explains both why significant GPS amplitude scintillations have been rarely observed at high latitudes (e.g., References $[20,33,96])$, and why different profiles of amplitude scintillation indices were recorded at SANAE IV and at Concordia during 8 September 2017.

The moderate/intense amplitude scintillations observed at SANAE IV can be ascribed to the TOI fragmentation process, which seems to be more effective for producing small scale irregularities at the cusp due to the increase in particle precipitation and FAC activity driven by the $B_{Z, I M F}$ negative excursion.

Concerning the definition of scintillations as solely due to diffractive effects, the $\sigma_{\varphi}$ high values, recorded without a simultaneous enhancement of $S_{4}$, are considered as not being scintillations but phase fluctuations that are due to the inadequacy of the detrending filtering, with a cutoff frequency fixed at $0.1 \mathrm{~Hz}$, to remove fluctuations associated with the high velocity of the ionospheric structures [29].

The behavior of the $S_{4}$ profile recorded at Concordia is perfectly consistent with the receiver's field of view that looks at the polar cap during the investigated period. Indeed, since the polar cap represents the area encompassing the ground projection of the Earth's magnetic field lines directly connected with the IMF, it is more exposed to both particle precipitation and solar wind variability than the auroral region. These 
conditions greatly augment the variability of plasma dynamics by increasing the likelihood of observing local variations of the ionospheric dynamics sufficient to generate small-scale irregularities [97-101].

In conclusion, the outcomes of our study can be summarized as follows:

1. Amplitude scintillation occurred together with phase scintillation at auroral latitudes under condition where the auroral oval expanded to the field of view of the GNSS observatory during geomagnetic storm.

2. Phase scintillation occurred without concurrent amplitude scintillation under conditions when the background electron density was insufficient to produce intense irregularities with scale sizes of the first Fresnel radius.

3. Moderate to intense amplitude scintillations were triggered by conspicuous increase in ionization as observed through unusually high TEC values at the auroral latitudes. This confirmed the theoretical prerequisite of sufficient background TEC for E-field variations associated with precipitation to form electron density irregularities with scale sizes of the order of the first Fresnel radius.

4. The physical processes triggering amplitude scintillations at high and low latitudes are similar. However, since the ionosphere-magnetosphere-solar wind coupling acts in different ways in the two regions, the conditions necessary for the observation of amplitude scintillations at high latitudes are high levels of ionization and a strong plasma dynamics driven by fast oscillations in $B_{z, I M F}$ (of the order of ten minutes) resulting in geomagnetic storms, which typically occur during high solar activity.

The characterization of the plasma conditions at high latitudes during geomagnetic storms, derived from this work, is propaedeutic to the characterization of the electromagnetic field near and inside the auroral oval and at higher latitudes. Such characterization could be benefit the calibration of instruments on board the China Seismo-Electromagnetic Satellite CSES-02 to facilitate collection of calibrated data at high latitudes.

Author Contributions: G.D., conceptualization, writing—original draft preparation, formal analysis and methodology, and investigation; M.P. (Mirko Piersanti), writing—review and editing, validation and supervision; A.P., writing—review and editing, investigation; I.C., validation, writing-review and editing; P.D.M., writing - review and editing, investigation; R.T., writing — review and editing, and investigation; M.P. (Michael Pezzopane), writing—-review and editing; L.A., validation, writingreview and editing; P.C., data curation, and writing - review and editing; P.U., project administration, and writing-review and editing. All authors have read and agreed to the published version of the manuscript.

Funding: This research received no external funding.

Data Availability Statement: GNSS data from the Septentrio PolaRxS ISMRs located at Concordia station and SANAE IV base can be obtained from the eSWua website (www.eswua.ingv.it, accessed on 21 June 2021) doi.org/10.13127/. The IMF and solar wind data are provided by the NASA OMNIWeb service (http:/ / omniweb.gsfc.nasa.gov, accessed on 21 June 2021). The $A E, A U$ and $A L$ indices were obtained from the World Data Center for Geomagnetism at Kyoto University (http:/ / wdc.kugi.kyoto-u.ac.jp/, accessed on 21 June 2021). The GPS TEC data used to construct TEC maps can be obtained through the UNAVCO Data Center (https:/ /www.unavco.org/data/gpsgnss / gps-gnss.html, accessed on 21 June 2021). The Special Sensor Ultraviolet Spectrographic Imager (SSUSI) data are available and documented at https://ssusi.jhuapl.edu, accessed on 21 June 2021. The SSUSI Principal Investigator is Dr. Larry J. Paxton. Swarm data are provided by the European Space Agency upon registration (https:/ / earth.esa.int/web/guest/swarm/data-access/, accessed on 21 June 2021). The British Antarctic Survey provides SuperDARN data via ftp, upon registration (https://www.bas.ac.uk/project/superdarn/\#data, accessed on 21 June 2021).The data collected by the magnetometer located at Dome $\mathrm{C}$ (DMC) are provided by INTERMAGNET (the International Real-time Magnetic Observatory Network, www.intermagnet.org, accessed on 21 June 2021). The data from the fluxgate magnetometer at SANAE IV can be obtained from the SANDIMS Data portal (https:/ / sandims.sansa.org.za/, accessed on 21 June 2021). 
Acknowledgments: G. D'Angelo and M. Piersanti thank the Italian Space Agency for the financial support under the contract ASI "LIMADOU scienza +" $n^{\circ}$ 2020-31-HH.0. G. D' Angelo and M. Piersanti thank the ISSI-BJ project "the electromagnetic data validation and scientific application research based on CSES satellite" and Dragon 5 cooperation 2020-2024 (ID. 59236). Paola De Michelis and Roberta Tozzi thank the Italian PNRA for the financial support under contract PNRA18_00289-A "Space weather in Polar Ionosphere: The Role of Turbulence". The authors thank PNRA (Programma Nazionale di Ricerche in Antartide) for supporting the upper atmosphere observations at Mario Zucchelli Station and Concordia Station (Antarctica). The authors acknowledge the eSWua system (www.eswua.ingv.it, accessed on 21 June 2021) owned by the Istituto Nazionale di Geofisica e Vulcanologia (INGV) and operated by the Upper Atmosphere Physics and Radiopropagation group. The authors acknowledge the use of SuperDARN data. SuperDARN is a collection of radars funded by national scientific funding agencies of Australia, Canada, China, France, Italy, Japan, Norway, South Africa, United Kingdom and the United States of America. The results presented in this paper rely on the data collected at Dome C (DMC). We thank the Ecole et Observatoire des Sciences de la Terre (EOST) and the Istituto Nazionale di Geofisica e Vulcanoligia (INGV) for supporting its operation and INTERMAGNET for promoting high standards of magnetic observatory practice (www.intermagnet.org, accessed on 21 June 2021).

Conflicts of Interest: The authors declare no conflict of interest.

\section{References}

1. Yeh, K.C.; Liu, C.-H. Radio wave scintillations in the ionosphere. Proc. IEEE 1982, 70, 324-360.

2. Wernik, A.; Secan, J.; Fremouw, E. Ionospheric irregularities and scintillation. Adv. Space Res. 2003, 31, 971-981. [CrossRef]

3. Kintner, P.M.; Ledvina, B.M.; De Paula, E. GPS and ionospheric scintillations. Space Weather 2007, 5. [CrossRef]

4. Mushini, S.C.; Jayachandran, P.; Langley, R.; MacDougall, J.; Pokhotelov, D. Improved amplitude-and phase-scintillation indices derived from wavelet detrended high-latitude GPS data. GPS Solut. 2012, 16, 363-373. [CrossRef]

5. Basu, S.; Groves, K.; Basu, S.; Sultan, P. Specification and forecasting of scintillations in communication/navigation links: Current status and future plans. J. Atmos. Sol. Terr. Phys. 2002, 64, 1745-1754. [CrossRef]

6. Kintner, P.; Humphreys, T.; Hinksn, J. GNSS and Ionospheric Scintillation: How to survive the next solar maximum. InsideGNSS 2009, 1, 22-30.

7. Spogli, L.; Alfonsi, L.; Cilliers, P.J.; Correia, E.; De Franceschi, G.; Mitchell, C.N.; Romano, V.; Kinrade, J.; Cabrera, M.A. GPS scintillations and total electron content climatology in the southern low, middle and high latitude regions. Ann. Geophys. 2013, 56, 0220.

8. Alfonsi, L.; Spogli, L.; De Franceschi, G.; Romano, V.; Aquino, M.; Dodson, A.; Mitchell, C.N. Bipolar climatology of GPS ionospheric scintillation at solar minimum. Radio Sci. 2011, 46. [CrossRef]

9. Jakowski, N.; Béniguel, Y.; De Franceschi, G.; Pajares, M.H.; Jacobsen, K.S.; Stanislawska, I.; Tomasik, L.; Warnant, R.; Wautelet, G. Monitoring, tracking and forecasting ionospheric perturbations using GNSS techniques. J. Space Weather Space Clim. 2012, 2, A22. [CrossRef]

10. Spogli, L.; Alfonsi, L.; De Franceschi, G.; Romano, V.; Aquino, M.; Dodson, A. Climatology of GNSS ionospheric scintillation at high and mid latitudes under different solar activity conditions. Il Nuovo Cim. 2010. [CrossRef]

11. Spogli, L.; Alfonsi, L.; Franceschi, G.D.; Romano, V.; Aquino, M.; Dodson, A. Climatology of GPS ionospheric scintillations over high and mid-latitude European regions. Ann. Geophys. 2009, 27, 3429-3437. [CrossRef]

12. Kinrade, J.; Mitchell, C.N.; Smith, N.D.; Ebihara, Y.; Weatherwax, A.T.; Bust, G.S. GPS phase scintillation associated with optical auroral emissions: First statistical results from the geographic South Pole. J. Geophys. Res. Space Phys. 2013, 118, $2490-2502$. [CrossRef]

13. Moen, J.; Oksavik, K.; Alfonsi, L.; Daabakk, Y.; Romano, V.; Spogli, L. Space weather challenges of the polar cap ionosphere. J. Space Weather Space Clim. 2013, 3, A02. [CrossRef]

14. van der Meeren, C.; Oksavik, K.; Lorentzen, D.A.; Rietveld, M.T.; Clausen, L.B. Severe and localized GNSS scintillation at the poleward edge of the nightside auroral oval during intense substorm aurora. J. Geophys. Res. Space Phys. 2015, $120,10-607$. [CrossRef]

15. Correia, E.; Spogli, L.; Alfonsi, L.; Cesaroni, C.; Gulisano, A.M.; Thomas, E.G.; Ramirez, R.F.H.; Rodel, A.A. Ionospheric F-region response to the 26 September 2011 geomagnetic storm in the Antarctica American and Australian sectors. Ann. Geophys. 2017, 35, 1113-1129. [CrossRef]

16. D'Angelo, G.; Piersanti, M.; Alfonsi, L.; Spogli, L.; Clausen, L.B.N.; Coco, I.; Li, G.; Baiqi, N. The response of high latitude ionosphere to the 2015 St. Patrick's day storm from in situ and ground based observations. Adv. Space Res. 2018, 62, 638-650. [CrossRef]

17. D'Angelo, G.; Piersanti, M.; Alfonsi, L.; Spogli, L.; Coco, I.; Li, G.; Baiqi, N. The response of high latitude ionosphere to the 2015 June 22 storm. Ann. Geophys. 2019, 62, 454. [CrossRef] 
18. De Franceschi, G.; Alfonsi, L.; Romano, V.; Aquino, M.; Dodson, A.; Mitchell, C.N.; Spencer, P.; Wernik, A.W. Dynamics of high-latitude patches and associated small-scale irregularities during the October and November 2003 storms. J. Atmos. Sol. Terr. Phys. 2008, 70, 879-888. [CrossRef]

19. Kinrade, J.; Mitchell, C.; Yin, P.; Smith, N.; Jarvis, M.; Maxfield, D.; Rose, M.; Bust, G.; Weatherwax, A. Ionospheric scintillation over Antarctica during the storm of 5-6 April 2010. J. Geophys. Res. Space Phys. 2012, 117. [CrossRef]

20. Mitchell, C.N.; Alfonsi, L.; De Franceschi, G.; Lester, M.; Romano, V.; Wernik, A.W. GPS TEC and scintillation measurements from the polar ionosphere during the October 2003 storm. Geophys. Res. Lett. 2005, 32. [CrossRef]

21. Prikryl, P.; Ghoddousi-Fard, R.; Thomas, E.; Ruohoniemi, J.; Shepherd, S.; Jayachandran, P.; Danskin, D.; Spanswick, E.; Zhang, Y.; Jiao, Y. GPS phase scintillation at high latitudes during geomagnetic storms of 7-17 March 2012-Part 1: The North American sector. Ann. Geophys. 2015, 33, 637-656. [CrossRef]

22. Prikryl, P.; Jayachandran, P.T.; Mushini, S.C.; Chadwick, R. Climatology of GPS phase scintillation and HF radar backscatter for the high-latitude ionosphere under solar minimum conditions. Ann. Geophys. 2011, 29, 377-392. [CrossRef]

23. Prikryl, P.; Zhang, Y.; Ebihara, Y.; Ghoddousi-Fard, R.; Jayachandran, P.T.; Kinrade, J.; Mitchell, C.N.; Weatherwax, A.T.; Bust, G.; Cilliers, P.J. An interhemispheric comparison of GPS phase scintillation with auroral emission observed at South Pole and from DMSP satellite. Ann. Geophys. 2013, 56. [CrossRef]

24. Van Dierendonck, A.; Klobuchar, J.; Hua, Q. Ionospheric scintillation monitoring using commercial single frequency C/A code receivers. ION GPS 1993, 93, 1333-1342.

25. Fremouw, E.; Leadabrand, R.; Livingston, R.; Cousins, M.; Rino, C.; Fair, B.; Long, R. Early results from the DNA Wideband satellite experiment-Complex-signal scintillation. Radio Sci. 1978, 13, 167-187. [CrossRef]

26. Prikryl, P.; Jayachandran, P.T.; Mushini, S.C.; Richardson, I.G. High-latitude GPS phase scintillation and cycle slips during high-speed solar wind streams and interplanetary coronal mass ejections: A superposed epoch analysis. Earth Planets Space 2014, 66, 1-10. [CrossRef]

27. Ghobadi, H.; Spogli, L.; Alfonsi, L.; Cesaroni, C.; Cicone, A.; Linty, N.; Romano, V.; Cafaro, M. Disentangling ionospheric refraction and diffraction effects in GNSS raw phase through fast iterative filtering technique. GPS Solut. 2020, 24, 1-13. [CrossRef]

28. De Franceschi, G.; Spogli, L.; Alfonsi, L.; Romano, V.; Cesaroni, C.; Hunstad, I. The ionospheric irregularities climatology over Svalbard from solar cycle 23. Sci. Rep. 2019, 9, 1-14. [CrossRef] [PubMed]

29. Spogli, L.; Ghobadi, H.; Cicone, A.; Alfonsi, L.; Cesaroni, C.; Linty, N.; Romano, V.; Cafaro, M. Adaptive Phase Detrending for GNSS Scintillation Detection: A Case Study Over Antarctica. IEEE Geosci. Remote Sens. Lett. 2021. [CrossRef]

30. Doherty, P.H.; Delay, S.H.; Valladares, C.E.; Klobuchar, J.A. Ionospheric scintillation effects in the equatorial and auroral regions. In Proceedings of the 13th International Technical Meeting of the Satellite Division of The Institute of Navigation (ION GPS 2000), Salt Lake City, UT, USA, 19-22 September 2000; pp. 662-671.

31. Jin, Y.; Moen, J.I.; Miloch, W.J. On the collocation of the cusp aurora and the GPS phase scintillation: A statistical study. J. Geophys. Res. Space Phys. 2015, 120, 9176-9191. [CrossRef]

32. MacDougall, J.; Jayachandran, P. Polar cap convection relationships with solar wind. Radio Sci. 2001, 36, 1869-1880. [CrossRef]

33. Forte, B.; Radicella, S.M. Problems in data treatment for ionospheric scintillation measurements. Radio Sci. 2002, 37, 8-1-8-5. [CrossRef]

34. Cesaroni, C.; De Franceschi, G.; Marcocci, C.; Pica, E.; Romano, V.; Spogli, L. Electronic Space Weather Upper Atmosphere Database (eSWua)—GNSS Scintillation Data, Version 1.0 (Version 1.0); Istituto Nazionale di Geofisica e Vulcanologia (INGV): Roma, Italy, 2020. [CrossRef]

35. Baker, K.; Wing, S. A new magnetic coordinate system for conjugate studies at high latitudes. J. Geophys. Res. Space Phys. 1989, 94, 9139-9143. [CrossRef]

36. Alfonsi, L.; Cilliers, P.; Romano, V.; Hunstad, I.; Correia, E.; Linty, N.; Dovis, F.; Terzo, O.; Ruiu, P.; Ward, J. First observations of GNSS ionospheric scintillations from DemoGRAPE project. Space Weather 2016, 14, 704-709. [CrossRef]

37. Bougard, B.; Sleewaegen, J.; Spogli, L.; Veettil, S.V.; Monico, J. CIGALA: Challenging the solar maximum in Brazil with PolaRxS. In Proceedings of the 24th International Technical Meeting of the Satellite Division of the Institute of Navigation (ION GNSS 2011), Portland, OR, USA, 20-23 September 2011; pp. 2572-2579.

38. D'Angelo, G.; Spogli, L.; Cesaroni, C.; Sgrigna, V.; Alfonsi, L.; Aquino, M. GNSS data filtering optimization for ionospheric observation. Adv. Space Res. 2015, 56, 2552-2562. [CrossRef]

39. Smith, A.M.; Mitchell, C.N.; Watson, R.J.; Meggs, R.W.; Kintner, P.M.; Kauristie, K.; Honary, F. GPS scintillation in the high arctic associated with an auroral arc. Space Weather 2008, 6. [CrossRef]

40. Ciraolo, L.; Azpilicueta, F.; Brunini, C.; Meza, A.; Radicella, S. Calibration errors on experimental slant total electron content (TEC) determined with GPS. J. Geod. 2007, 81, 111-120. [CrossRef]

41. Cesaroni, C.; Spogli, L.; Alfonsi, L.; De Franceschi, G.; Ciraolo, L.; Monico, J.F.G.; Scotto, C.; Romano, V.; Aquino, M.; Bougard, B. L-band scintillations and calibrated total electron content gradients over Brazil during the last solar maximum. J. Space Weather Space Clim. 2015, 5, A36. [CrossRef]

42. Wernik, A.W.; Alfonsi, L.; Materassi, M. Ionospheric irregularities, scintillation and its effect on systems. Acta Geophys. Pol. 2004, 52, 237-249.

43. Zou, Y.; Wang, D. A study of GPS ionospheric scintillations observed at Guilin. J. Atmos. Sol. Terr. Phys. 2009, 71, 1948-1958. [CrossRef] 
44. Paxton, L.J.; Meng, C.-I.; Fountain, G.H.; Ogorzalek, B.S.; Darlington, E.H.; Gary, S.A.; Goldsten, J.O.; Kusnierkiewicz, D.Y.; Lee, S.C.; Linstrom, L.A. SSUSI: Horizon-to-horizon and limb-viewing spectrographic imager for remote sensing of environmental parameters. Ultrav. Technol. IV 1993, 161-176. [CrossRef]

45. Paxton, L.J.; Schaefer, R.K.; Zhang, Y.; Kil, H. Far ultraviolet instrument technology. J. Geophys. Res. Space Phys. 2017, 122, 2706-2733. [CrossRef]

46. Jin, Y.; Oksavik, K. GPS scintillations and losses of signal lock at high latitudes during the 2015 St. Patrick's Day storm. J. Geophys. Res. Space Phys. 2018, 123, 7943-7957. [CrossRef]

47. Greenwald, R.; Baker, K.; Dudeney, J.; Pinnock, M.; Jones, T.; Thomas, E.; Villain, J.-P.; Cerisier, J.-C.; Senior, C.; Hanuise, C. Darn/superdarn. Space Sci. Rev. 1995, 71, 761-796. [CrossRef]

48. Knudsen, D.; Burchill, J.; Buchert, S.; Eriksson, A.; Gill, R.; Wahlund, J.E.; Åhlén, L.; Smith, M.; Moffat, B. Thermal ion imagers and Langmuir probes in the Swarm electric field instruments. J. Geophys. Res. Space Phys. 2017, 122, 2655-2673. [CrossRef]

49. Spicher, A.; Clausen, L.B.N.; Miloch, W.J.; Lofstad, V.; Jin, Y.; Moen, J.I. Interhemispheric study of polar cap patch occurrence based on Swarm in situ data. J. Geophys. Res. Space Phys. 2017, 122, 3837-3851. [CrossRef]

50. King, J.; Papitashvili, N. Solar wind spatial scales in and comparisons of hourly Wind and ACE plasma and magnetic field data. J. Geophys. Res. Space Phys. 2005, 110. [CrossRef]

51. Davis, T.N.; Sugiura, M. Auroral electrojet activity index AE and its universal time variations. J. Geophys. Res. 1966, 71, 785-801. [CrossRef]

52. Starodubtsev, S.; Baishev, D.; Grigoryev, V.; Karimov, R.; Kozlov, V.; Korsakov, A.; Makarov, G.; Moiseev, A. Analyzing solar, cosmic, and geophysical events in September 2017, using SHICRA SB RAS complex observations. Sol. Terr. Phys. 2019, 5, 14-27.

53. Tassev, Y.; Velinov, P.I.; Tomova, D.; Mateev, L. Analysis of extreme solar activity in early september 2017: G4-severe geomagnetic storm (07-08.09) and GLE72 (10.09) in solar minimum. Comptes Rendus De L'académie Bulg. Des Sci. 2017, 70, $1437-1444$.

54. Piersanti, M.; Di Matteo, S.; Carter, B.; Currie, J.; D'Angelo, G. Geoelectric field evaluation during the September 2017 Geomagnetic Storm: MA. I. GIC. model. Space Weather 2019, 17, 1241-1256. [CrossRef]

55. Akasofu, S.-I. Auroral substorms: Search for processes causing the expansion phase in terms of the electric current approach. Space Sci. Rev. 2017, 212, 341-381. [CrossRef]

56. Cherniak, I.; Zakharenkova, I. Dependence of the high-latitude plasma irregularities on the auroral activity indices: A case study of 17 March 2015 geomagnetic storm. Earth Planets Space 2015, 67, 1-12. [CrossRef]

57. Ho, C.; Mannucci, A.; Sparks, L.; Pi, X.; Lindqwister, U.; Wilson, B.; Iijima, B.; Reyes, M. Ionospheric total electron content perturbations monitored by the GPS global network during two northern hemisphere winter storms. J. Geophys. Res. Space Phys. 1998, 103, 26409-26420. [CrossRef]

58. Jin, Y.; Moen, J.I.; Oksavik, K.; Spicher, A.; Clausen, L.B.; Miloch, W.J. GPS scintillations associated with cusp dynamics and polar cap patches. J. Space Weather Space Clim. 2017, 7, A23. [CrossRef]

59. Oksavik, K.; van der Meeren, C.; Lorentzen, D.A.; Baddeley, L.; Moen, J. Scintillation and loss of signal lock from poleward moving auroral forms in the cusp ionosphere. J. Geophys. Res. Space Phys. 2015, 120, 9161-9175. [CrossRef]

60. Basu, S.; Groves, K.; Quinn, J.; Doherty, P. A comparison of TEC fluctuations and scintillations at Ascension Island. J. Atmos. Sol. Terr. Phys. 1999, 61, 1219-1226. [CrossRef]

61. Fæhn Follestad, A.; Herlingshaw, K.; Ghadjari, H.; Knudsen, D.J.; McWilliams, K.A.; Moen, J.I.; Spicher, A.; Wu, J.; Oksavik, K. Dayside Field-Aligned Current Impacts on Ionospheric Irregularities. Geophys. Res. Lett. 2020, 47, e2019GL086722. [CrossRef]

62. Kintner, P.M.; Seyler, C.E. The status of observations and theory of high latitude ionospheric and magnetospheric plasma turbulence. Space Sci. Rev. 1985, 41, 91-129. [CrossRef]

63. Basu, S.; Basu, S.; MacKenzie, E.; Coley, W.; Sharber, J.; Hoegy, W. Plasma structuring by the gradient drift instability at high latitudes and comparison with velocity shear driven processes. J. Geophys. Res. Space Phys. 1990, 95, 7799-7818. [CrossRef]

64. Yuan, Z.; Zhao, L.; Xiong, Y.; Deng, X.; Wang, J. Energetic particle precipitation and the influence on the sub-ionosphere in the SED plume during a super geomagnetic storm. J. Geophys. Res. Space Phys. 2011, 116. [CrossRef]

65. Yuan, Z.G.; Deng, X.H.; Zhang, S.R.; Wan, W.X.; Reinisch, B.W. F region behavior in the SED plume during a geomagnetic superstorm: A case study. J. Geophys. Res. Space Phys. 2009, 114. [CrossRef]

66. Foster, J.C. Ionospheric signatures of magnetospheric convection. J. Geophys. Res. Space Phys. 1984, 89, 855-865. [CrossRef]

67. Foster, J.C. Plasma Transport through the Dayside Cleft: A Source of Ionization Patches in the Polar Cap. In Electromagnetic Coupling in the Polar Clefts and Caps; NATO ASI Series (C: Mathematical and Physical Sciences); Sandholt, P.E., Egeland, A., Eds.; Springer: Dordrecht, The Netherlands, 1989; Volume 278. [CrossRef]

68. Sato, T. Morphology of ionospheric F2 disturbances in the polar regions, A linkage between polar patches and plasmaspheric drainage plumes. Rep. Ionos. Res. Space Res. Jpn 1959, 131, 91.

69. Liu, J.; Wang, W.; Burns, A.; Solomon, S.C.; Zhang, S.; Zhang, Y.; Huang, C. Relative importance of horizontal and vertical transports to the formation of ionospheric storm-enhanced density and polar tongue of ionization. J. Geophys. Res. Space Phys. 2016, 121, 8121-8133. [CrossRef]

70. Liu, J.; Wang, W.; Burns, A.; Liu, L.; McInerney, J. A TIEGCM numerical study of the source and evolution of ionospheric F-region tongues of ionization: Universal time and interplanetary magnetic field dependence. J. Atmos. Sol. Terr. Phys. 2017, 156, 87-96. [CrossRef] 
71. Consolini, G.; De Michelis, P.; Alberti, T.; Giannattasio, F.; Coco, I.; Tozzi, R.; Chang, T. On the Multifractal Features of LowFrequency Magnetic Field Fluctuations in the Field-Aligned Current Ionospheric Polar Regions: Swarm Observations. J. Geophys. Res. Space Phys. 2020, 125, e2019JA027429. [CrossRef]

72. Meziane, K.; Kashcheyev, A.; Patra, S.; Jayachandran, P.; Hamza, A. Solar Cycle Variations of GPS Amplitude Scintillation for the Polar Region. Space Weather 2020, 18, e2019SW002434. [CrossRef]

73. Ruohoniemi, J.; Baker, K. Large-scale imaging of high-latitude convection with Super Dual Auroral Radar Network HF radar observations. J. Geophys. Res. Space Phys. 1998, 103, 20797-20811. [CrossRef]

74. Cousins, E.; Shepherd, S. A dynamical model of high-latitude convection derived from SuperDARN plasma drift measurements. J. Geophys. Res. Space Phys. 2010, 115. [CrossRef]

75. Villain, J.; Hanuise, C.; Beghin, C. ARCAD 3-SAFARI coordinated study of auroral and polar F-region ionospheric irregularities. Ann. Geophys. 0755, 4, 61-68.

76. Kelley, M.C.; Vickrey, J.F.; Carlson, C.; Torbert, R. On the origin and spatial extent of high-latitude F region irregularities. J. Geophys. Res. Space Phys. 1982, 87, 4469-4475. [CrossRef]

77. Pfaff, R.; Kelley, M.; Fejer, B.G.; Kudeki, E.; Carlson, C.; Pedersen, A.; Hausler, B. Electric field and plasma density measurements in the auroral electrojet. J. Geophys. Res. Space Phys. 1984, 89, 236-244. [CrossRef]

78. Sahr, J.; Fejer, B.G. Auroral electrojet irregularity theory and experiment: A critical review of present understanding and future directions. J. Geophys. Res. 1996, 101, 893. [CrossRef]

79. De Michelis, P.; Consolini, G.; Pignalberi, A.; Tozzi, R.; Coco, I.; Giannattasio, F.; Pezzopane, M.; Balasis, G. Looking for a proxy of the ionospheric turbulence with Swarm data. Sci. Rep. 2021, 11, 1-12. [CrossRef]

80. Mrak, S.; Semeter, J.; Hirsch, M.; Starr, G.; Hampton, D.; Varney, R.H.; Reimer, A.S.; Swoboda, J.; Erickson, P.J.; Lind, F. Field-aligned GPS scintillation: Multisensor data fusion. J. Geophys. Res. Space Phys. 2018, 123, 974-992. [CrossRef]

81. Jin, Y.; Moen, J.I.; Miloch, W.J. GPS scintillation effects associated with polar cap patches and substorm auroral activity: Direct comparison. J. Space Weather Space Clim. 2014, 4, A23. [CrossRef]

82. Jin, Y.; Moen, J.I.; Miloch, W.J.; Clausen, L.B.; Oksavik, K. Statistical study of the GNSS phase scintillation associated with two types of auroral blobs. J. Geophys. Res. Space Phys. 2016, 121, 4679-4697. [CrossRef]

83. Oppenheim, A.V.; Buck, J.R.; Schafer, R.W. Discrete-Time Signal Processing; Prentice Hall: Upper Saddle River, NJ, USA, 2001; Volume 2.

84. Spogli, L.; Piersanti, M.; Cesaroni, C.; Materassi, M.; Cicone, A.; Alfonsi, L.; Romano, V.; Ezquer, R.G. Role of the external drivers in the occurrence of low-latitude ionospheric scintillation revealed by multi-scale analysis. J. Space Weather Space Clim. 2019, 9, A35. [CrossRef]

85. de Oliveira Moraes, A.; Costa, E.; Abdu, M.A.; Rodrigues, F.S.; de Paula, E.R.; Oliveira, K.; Perrella, W.J. The variability of low-latitude ionospheric amplitude and phase scintillation detected by a triple-frequency GPS receiver. Radio Sci. 2017, 52, 439-460. [CrossRef]

86. Weber, E.; Klobuchar, J.; Buchau, J.; Carlson, H., Jr.; Livingston, R.; de La Beaujardiere, O.; McCready, M.; Moore, J.; Bishop, G. Polar cap F layer patches: Structure and dynamics. J. Geophys. Res. Space Phys. 1986, 91, 12121-12129. [CrossRef]

87. Weber, E.; Tsunoda, R.; Buchau, J.; Sheehan, R.; Strickland, D.; Whiting, W.; Moore, J. Coordinated measurements of auroral zone plasma enhancements. J. Geophys. Res. Space Phys. 1985, 90, 6497-6513. [CrossRef]

88. Weber, E.J.; Buchau, J.; Moore, J.; Sharber, J.; Livingston, R.; Winningham, J.D.; Reinisch, B. F layer ionization patches in the polar cap. J. Geophys. Res. Space Phys. 1984, 89, 1683-1694. [CrossRef]

89. Ruohoniemi, J.; Greenwald, R. Dependencies of high-latitude plasma convection: Consideration of interplanetary magnetic field, seasonal, and universal time factors in statistical patterns. J. Geophys. Res. Space Phys. 2005, 110. [CrossRef]

90. Stone, W.R. Critical review of ionospheric patches and blobs. In Review of Radio Science 1993-1996; Stone, W.R. URSI: Ghent, Belgium, 1996.

91. Crowley, G.; Ridley, A.; Deist, D.; Wing, S.; Knipp, D.; Emery, B.; Foster, J.; Heelis, R.; Hairston, M.; Reinisch, B. Transformation of high-latitude ionospheric F region patches into blobs during the March 21, 1990, storm. J. Geophys. Res. Space Phys. 2000, 105, 5215-5230. [CrossRef]

92. Rodger, A.; Graham, A. Diurnal and seasonal occurrence of polar patches. Ann. Geophys. 1996, 14, 533-537. [CrossRef]

93. De Michelis, P.; Consolini, G.; Tozzi, R.; Marcucci, M.F. Scaling Features of High-Latitude Geomagnetic Field Fluctuations at Swarm Altitude: Impact of IMF Orientation. J. Geophys. Res. Space Phys. 2017, 122, 10-548. [CrossRef]

94. De Michelis, P.; Consolini, G.; Tozzi, R.; Marcucci, M.F. Observations of high-latitude geomagnetic field fluctuations during St. Patrick's Day storm: Swarm and SuperDARN measurements. Earth Planets Space 2016, 68, 1-16. [CrossRef]

95. Carrano, C.S.; Groves, K.M.; Caton, R.G.; Rino, C.L.; Straus, P.R. Multiple phase screen modeling of ionospheric scintillation along radio occultation raypaths. Radio Sci. 2011, 46, 1-14. [CrossRef]

96. van der Meeren, C.; Oksavik, K.; Lorentzen, D.; Moen, J.I.; Romano, V. GPS scintillation and irregularities at the front of an ionization tongue in the nightside polar ionosphere. J. Geophys. Res. Space Phys. 2014, 119, 8624-8636. [CrossRef]

97. De Michelis, P.; Pignalberi, A.; Consolini, G.; Coco, I.; Tozzi, R.; Pezzopane, M.; Giannattasio, F.; Balasis, G. On the 2015 St. Patrick's Storm Turbulent State of the Ionosphere: Hints from the Swarm Mission. J. Geophys. Res. Space Phys. 2020, 125, e2020JA027934. [CrossRef] 
98. Consolini, G.; De Michelis, P.; Alberti, T.; Coco, I.; Giannattasio, F.; Tozzi, R.; Carbone, V. Intermittency and Passive Scalar Nature of Electron Density Fluctuations in the High-Latitude Ionosphere at Swarm Altitude. Geophys. Res. Lett. 2020, 47, e2020GL089628. [CrossRef]

99. Consolini, G.; Tozzi, R.; De Michelis, P.; Coco, I.; Giannattasio, F.; Pezzopane, M.; Marcucci, M.F.; Balasis, G. High-latitude polar pattern of ionospheric electron density: Scaling features and IMF dependence. J. Atmos. Sol. Terr. Phys. 2021, 217, 105531. [CrossRef]

100. Spicher, A.; Miloch, W.; Clausen, L.; Moen, J. Plasma turbulence and coherent structures in the polar cap observed by the ICI-2 sounding rocket. J. Geophys. Res. Space Phys. 2015, 120, 10959-10978. [CrossRef]

101. Heppner, J.; Liebrecht, M.; Maynard, N.; Pfaff, R. High-latitude distributions of plasma waves and spatial irregularities from DE 2 alternating current electric field observations. J. Geophys. Res. Space Phys. 1993, 98, 1629-1652. [CrossRef] 